\title{
RELATÓRIO TÉCNICO DOS CRUZEIROS DO PROJETO VIEIRA. III. CRUZEIROS IV (MAIO DE 1996) A XIV (MAIO DE 1997)
}

\author{
PEZZUTO'1, P.R.; BORZONE², C.A.; ABRAHÃO², R.L.B.E.; BRANDINI², F. \& \\ E.C. MACHADO ${ }^{2}$
}

${ }^{1}$ CTTMar/UNIVALI, C.P.360, CEP 88302-202, Itajaí, SC. e-mail: pezzuto@mbox1.univali.rct-sc.br

${ }^{2}$ Centro de Estudos do Mar, Universidade Federal do Paraná, Av. Beira Mar s $\mathbf{n}{ }^{\circ}$, Pontal do Sul, CEP 83255-000, Pontal do Paraná, PR. RESUMO

\begin{abstract}
Neste relatório são apresentados os dados originais e principais resultados técnicos obtidos durante os Cruzeiros IV (maio de 1996) a XIV (maio de 1997) do Projeto Vieira. Os cruzeiros tiveram como objetivos principais a captura de vieiras para análise de seu crescimento, mortalidade, reprodução e evolução temporal da abundância do estoque nos dois bancos anteriormente identificados, bem como a análise das variações temporais da temperatura, salinidade, nutrientes inorgânicos dissolvidos e clorofila-a na coluna d'água, composição do fitoplâncton e microfitobentos, e características sedimentológicas (granulometria e teor de matéria orgânica e carbonatos) das respectivas áreas. Entre outubro e abril, observou-se a formação de uma forte termoclina resultante da intrusão da Água Central do Atlântico Sul (ACAS) sobre a plataforma continental interna. Nos demais meses, a coluna d'água mostrou-se termicamente bastante homogênea. A salinidade apresentou valores mínimos (ao redor de 30) em alguns meses de inverno, sendo que nos demais períodos houve o predomínio de salinidades superiores a 36 em toda a coluna. Concentrações de fosfato, nitrito, nitrato e clorofila-a foram maiores na água de fundo, sendo que os valores máximos de clorofila-a foram observados justamente durante a intrusão da ACAS sobre a área. O silicato apresentou padrões sazonais e batimétricos muito menos definidos do que os demais nutrientes. Ao longo do período observou-se poucas variações nas características granulométricas dos dois bancos, havendo o predomínio de areias finas a muito finas em ambas as áreas. Por outro lado, observou-se variações sazonais expressivas dos teores de carbonato de cálcio e matéria orgânica, esta última, com valores 8 vezes maiores na primavera e verão em relação às demais estações. Os maiores teores de carbonato de cálcio foram observados no outono e inverno. Após diversas modificações, obteve-se performances satisfatórias de captura de vieiras pelo beamtrawl, permitindo o acompanhamento temporal do recurso. Enquanto as abundâncias do estoque no Banco de São Francisco apresentaram-se reduzidas porém relativamente estáveis ao longo do tempo, verificou-se que o Banco de Bom Abrigo foi praticamente exaurido entre dezembro/95 e maio/96. Em decorrência do estado extremamente frágil do recurso, sugere-se que, baseando-se nos resultados complementares a serem obtidos no decorrer do projeto, medidas emergenciais sejam implementadas no sentido de evitar um possível colapso irreversível do recurso no sul do Brasil.
\end{abstract}

Palavras-chave: vieira, Pecten ziczac, prospecção pesqueira, nutrientes dissolvidos, sedimentologia, oceanografia física, Brasil.

\section{TECHNICAL REPORT OF THE SCALLOP PROJECT CRUISES. III. CRUISES IV (MAY, 1996) TO XIV (MAY, 1997)}

\author{
ABSTRACT \\ Main technical results and original data of the Scallop Project Cruises IV (May, 1996) to XIV \\ (May, 1997) are presented in this Report. The aims of the cruises were: a) to sample scallops for
}




\begin{abstract}
growth, mortality, recruitment and stock assessment analysis; b) to study environmental characteristics in the scallop beds, named, temperature, salinity, dissolved inorganic nutrients and chlorophyll-a profiles in the water column, phytoplankton and microphytobenthos composition, and grain size, percent of organic matter and calcium carbonates in the sediment. Contrasting with the homogeneus thermal profiles observed during the autumn and winter, a strong termocline developed between October and April, as resulting from the intrusion of the Southern Atlantic Central Water (SACW) on the inner shelf. Lowest salinities, around 30, were observed in some winter months, whereas values above 36 were found in the other periods. Phosfate, nitrite, nitrate and chlorophylla concentrations were highest in the bottom water, and the highests concentrations of chlorophylla were coincident with the SACW intrusion. Silicate concentrations did not show any seasonal or vertical pattern. Both beds showed little changes in the sediment grain size (mostly fine to very fine sands). On the other hand, percent of organic matter and calcium carbonate varied seasonally but with peaks in opposite periods, with an 8-fold increase in the organic matter content of the sediment from autumn/winter to spring/summer. After some modifications of the beam trawl structure, a good and regular efficience was attained to sample scallops. Pecten ziczac abundances in the São Francisco bed were low but relatively stable between December/95 (first cruise of the project) and May (1997). On the other hand, Bom Abrigo bed was completely collapsed between December/95 and May/96, showing catch rates of 1 ind. $\mathrm{hr}^{-1}$. Considering the extremely fragile condition of the resource, its suggested that emergencial actions be implemented in order to prevent an irreversible colapse of the resource in Southern Brazil.
\end{abstract}

Key-words: scallop, Pecten ziczac, Fishery survey, dissolved nutrients, sedimentology, physical oceanography, Brazil

\section{INTRODUÇÃO}

Este documento é o terceiro de uma série de relatórios sobre os cruzeiros científicos do Projeto Vieira, desenvolvido pelo Centro de Estudos do Mar da UFPR e pelo Centro de Ciências Tecnológicas, da Terra e do Mar da UNIVALI. Os cruzeiros têm sido realizados mensalmente desde dezembro de $1995 \mathrm{com}$ o N/Pq Diadorim (CEPSUL/IBAMA), com os objetivos de estudar as principais características da biologia e da dinâmica populacional da vieira Pecten ziczac no litoral sul do Brasil, reconhecer a situação atual do recurso, e determinar premissas básicas para o seu futuro manejo.

O projeto conta com o suporte financeiro das duas instituições acima mencionadas, do CEPSUL/IBAMA (SC), da International Foundation For Science (IFS - Research Grant Agreement No. A/2197-1), e da CAPES e CNPq, na forma de bolsas individuais de doutorado (Pós-graduação em Ciências Biológicas - Zoologia - UFPR) e pesquisa aos autores (P. R. P. e C. A. B., respectivamente).

Os resultados dos Cruzeiros 1, 2 e 3, realizados entre dezembro de 1995 e abril de
1996, foram publicados em Borzone \& Pezzuto (1997) e Pezzuto \& Borzone (1997). Este relatório apresenta os resultados alcançados durante a execução dos Cruzeiros 4 a 14, realizados entre maio de 1996 e maio de 1997.

\section{Objetivos dos cruzeiros}

Os três primeiros cruzeiros do projeto tiveram como objetivos principais mapear a área de ocorrência do recurso e testar a eficiência de alguns equipamentos para a captura da vieira. Ao longo dos mesmos, foram localizados dois bancos sendo um a leste da llha de São Francisco do Sul no litoral norte de Santa Catarina, (estação 3, Banco de São Francisco do Sul) e outro a sudeste da llha do Bom Abrigo, no sul de São Paulo (estação TM, Banco do Bom Abrigo) (Fig. 1).

Os cruzeiros posteriores, cujos resultados encontram-se descritos neste relatório, visaram a captura de vieiras ao longo de um ano para análise de seu crescimento, mortalidade, reprodução e evolução temporal da abundância do estoque nas duas áreas estudadas. Foram também analisadas as variações temporais da temperatura, salinidade, 
nutrientes inorgânicos dissolvidos e clorofilaa na coluna d'água, composição do fitoplâncton e microfitobentos, e características sedimentológicas (granulometria e teor de matéria orgânica e carbonatos) do fundo em cada um dos bancos.

\section{MATERIAL E MÉTODOS}

As especificações técnicas do navio, incluindo equipamentos de posicionamento e navegação podem ser encontradas no Relatório I (Borzone \& Pezzuto, 1997). Como equipamento de amostragem, utilizou-se o mesmo beam traw/ de maior porte (BG) empregado no segundo e terceiro cruzeiros, com dimensões de 1,90 x 0,50 m e abertura de maIha de $5 \mathrm{~cm}$ (vide Fig. 1. de Pezzuto \& Borzone, 1997). Ao longo dos três primeiros embarques procurou-se testar e aprimorar o equipamento através da alteração de características tanto da armação de metal, como da tralha e da

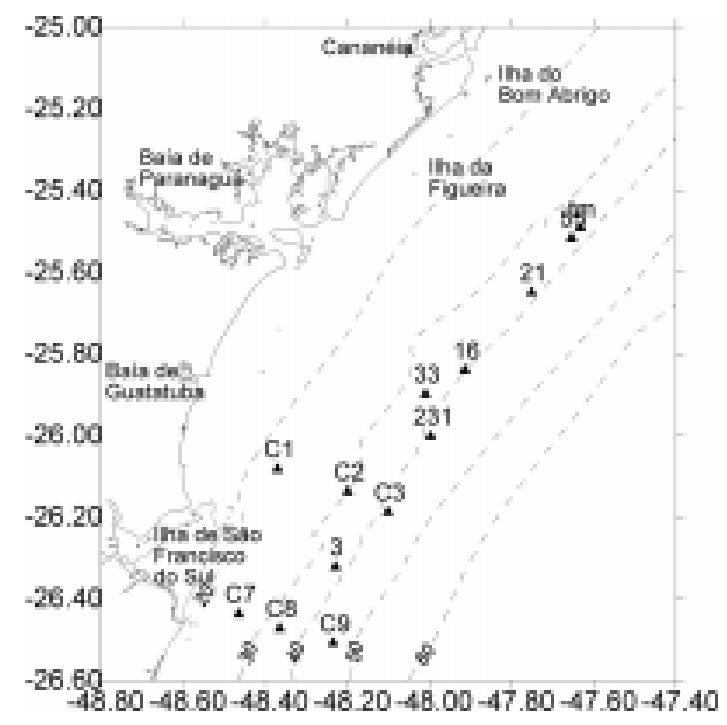

Figura 1. Distribuição das estações de amostragem e batimetria (em metros). Latitude e longitude são expressas como centésimos de grau $\left(00.00^{*}-1\right)$. As estações C4 e C5 encontram-se praticamente sobrepostas à estação 3, não sendo indicadas no mapa. rede. Entretanto, mesmo observando-se alguma melhoria nas capturas, o desempenho do aparelho mostrou-se apenas regular. Desta forma, ao longo dos dez cruzeiros subseqüentes foram efetuadas outras modificações no beam-trawl (Tabela 1) visando melhorar ainda mais a sua performance. Os arrastos foram efetuados em percurso reto a velocidades variáveis entre 3,0 e 4,0 nós, sendo mantido o comprimento de cabo de $300 \mathrm{~m}$ utilizado nos Cruzeiros 2 e 3 (Pezzuto \& Borzone, 1997). O processamento do material biológico obtido (vieiras e Chione pubera) seguiu a mesma metodologia empregada no Cruzeiro 1 (Borzone \& Pezzuto, 1997), excetuando-se a contagem das conchas destacadas de $C$. pubera, a qual não foi mais realizada a partir do Cruzeiro 4. A estação 3 (Fig. 1) foi amostrada em todos os cruzeiros, exceto 0 de dezembro de 1996, quando os arrastos na estação foram cancelados por mau tempo. Já a estação TM (Fig. 1) foi amostrada mensalmente até o Cruzeiro 7, passando então a ser amostrada a cada dois meses a partir do oitavo cruzeiro. Esporadicamente foram realizados arrastos adicionais em cinco outras estações (estações 231, 33, 16, 21 e 55; Fig. 1) para avaliar as abundâncias de vieiras entre os dois bancos principais.

Além das amostras de vieiras, foram obtidos nas estações 3 e TM: a) perfis de temperatura e salinidade com um mini-STD Sensordata; b) amostras de sedimento com um busca-fundo modelo Petit-Ponar para análise de granulometria, determinação dos teores de matéria orgânica e carbonatos e estudo da composição do microfitobentos; c) amostras da coluna d'água com garrafas de Niskin para análise da composição fitoplanctônica, e das concentrações de nutrientes dissolvidos (fosfato, silicato, nitrito e nitrato) e clorofila-a, em profundidades de 0, 10, $15,20,25,30$ e 40 metros, e; d) arrastos verticais com rede para fitoplâncton com malha de 25 micrômetros.

Durante o Cruzeiro 5 iniciou-se também o estudo temporal do assentamento de semen- 
Tabela 1. Modificações efetuadas no beam-traw/ utilizado nos diversos cruzeiros do Projeto Vieira a partir do Cruzeiro 4.

\begin{tabular}{cl}
\hline \hline Beam-trawl & \multicolumn{1}{c}{ Características } \\
\hline BG 5 & $\begin{array}{l}\text { Idênticas às da última configuração utilizada no Cruzeiro III, sendo porém } \\
\text { alterado o ponto de fixação da tesoura de aço ao beam-trawl. Na parte frontal } \\
\text { do aparelho, as manilhas de fixação foram deslocadas do segundo para o }\end{array}$ \\
& quarto furo de cima para baixo (vide Fig. 1 de Pezzuto \& Borzone, 1977), \\
& com o objetivo de forçar a permanência da tralha da rede junto ao fundo. \\
& Devido à melhoria de desempenho, este novo ponto de fixação das manilhas \\
& continuou a ser utilizado em todos os cruzeiros subseqüentes.
\end{tabular}

BG 6 Foram costuradas duas correntes de $9 \mathrm{~mm}$ de bitola à tralha de aço, uma esticada e outra formando pequenos seios por trás da tralha e por baixo da rede. Uma terceira corrente idêntica às anteriores foi utilizada como espantadeira. Um sobressaco de malha de $3 \mathrm{~cm}$ entre nós opostos esticados foi costurado por dentro da rede, tendo sido utilizado até o último cruzeiro para capturas de recrutas.

BG 7 A tralha utilizada no BG 6 foi modificada drasticamente após os três primeiros lances do Cruzeiro $\mathrm{V}$, devido à grande piora nas capturas. Todo $\mathrm{o}$ arranjo anterior foi desmontado, deixando-se apenas uma das correntes costurada à rede que teve também o seio aumentado. Passou-se a empregar duas correntes espantadeiras de bitola $9 \mathrm{~mm}$.

BG 8 Configuração idêntica à anterior, porém com a troca da bitola da corrente espantadeira anterior de 9 para $12 \mathrm{~mm}$.

BG 9 Configuração idêntica à anterior, porém sem a segunda corrente espantadeira ( $9 \mathrm{~mm}$ de bitola), perdida por acidente.

tes de $P$. ziczac em coletores artificiais. Estes consistiram de sistemas tipo long-line formados por uma linha principal flutuante, à qual foram fixados 10 pares de bolsas de ráfia preenchidas com sacos de poliestireno com maIha de $2 \mathrm{~mm}$. Os sistemas foram fixados através de mergulho autônomo em local próximo à Ilha da Figueira, localizada a nordeste da desembocadura da Baía de Paranaguá (Fig. 1). Segundo o planejamento inicial, a inspeção e substituição das bolsas estava prevista para ocorrer a cada três meses. Contudo, em virtude da prevalência de mal tempo em praticamente todos os cruzeiros subseqüentes, foi impossível o deslocamento da equipe até o local e a manutenção dos sistemas de captação, tendo-se decidido assim por interromper o experimento.

O processamento das amostras de sedimento e cálculo dos parâmetros granulométricos foi realizado como no Cruzeiro 1 (Borzone \& Pezzuto, 1997). Para determinação da clorofila-a, $200 \mathrm{ml}$ de água do mar de cada profundidade foram filtrados em filtro GF/C com auxílio de kit de filtração e bomba de vácuo manual, sendo os filtros acondicionados posteriormente em frasco com sílicagel e mantidos congelados em freezer até o momento da análise. A água filtrada foi acondicionada em frascos plásticos e congelada também até o momento da análise dos nutrientes dissolvidos. A extração de clorofila foi efetuada em laboratório conforme Parsons et al. (1984) e as concentrações de clorofila e feopigmentos obtidas conforme Arar \& Collins (1992) em fluorômetro Turner Designs 10-AU. Os nutrientes inorgânicos dissolvidos foram analisados pelas técnicas colorimétricas descritas em Parsons et al. (1984) e Grasshoff et al. (1983). 
A partir do Cruzeiro 9 (outubro de 1996), e visando otimizar a utilização da embarcação, foi realizada também pesca experimental de lulas e peixes demersais durante o dia em sete estações posicionadas na região do Banco de São Francisco com uma pequena rede camaroneira de portas (estações $\mathrm{C} 1, \mathrm{C} 2$, C3, C4, C5, C6, C7, C8 e C9; Fig. 1). Os dados de captura referentes a essas amostragens fazem parte de projeto específico dos pesquisadores do CTTMAR: José Angel Alvarez Perez, Humber Agrelli de Andrade e Marcelo Ribeiro, e não serão abordados neste relatório. Contudo, perfis de temperatura e salinidade foram executados nas suas estações extremas (C1, C3, C7 e C9), como forma de obter melhor descrição das variações temporais destes parâmetros na área de São Francisco do Sul, sendo os resultados apresentados abaixo.

\section{RESULTADOS}

Dados relativos aos cruzeiros, estações e tipos de amostragens efetuadas em cada ponto podem ser consultados na Tabela 2.

A análise das variações da temperatura e salinidade ao longo do período de estudo revelam a formação de uma forte termoclina entre outubro e abril em ambos os bancos, atingindo sua máxima expressão em fevereiro (Figs. 2 e 3). Este gradiente térmico desaparece com a homogeneização da coluna d'água durante o outono e inverno, de Maio a Setembro. As duas áreas apresentaram o mesmo ciclo de temperatura, sendo as maiores diferenças observadas no inverno, quando a estação 3 apresentou menores temperaturas de fundo em relação à estação TM (Figs. 2 e 3). Em geral, a salinidade mostrou pequenas variações ao longo da coluna d'água e um ciclo sazonal similar ao da temperatura. Valores mínimos, ao redor de 30, foram observados durante alguns meses de inverno (Agosto e início de Setembro/96). Durante os outros meses, a salinidade apresentou valores qua- se sempre acima de 36 em ambas as estações e em todas as profundidades. Quando a salinidade não se mostrou homogênea em toda a coluna d'água, em geral os menores valores foram encontrados em profundidades menores, sendo que nestes casos as diferenças de salinidades entre superfície e fundo nunca ultrapassaram 4 (Figs. 2 e 3).

Os perfís de temperatura e salinidade obtidos nas quatro estações extremas da grade de amostragem de lulas (estações C1, C3, $\mathrm{C} 7$ e C9) (Fig. 1), permitiram visualizar com maior clareza o fenômeno de formação e desaparecimento da termoclina entre profundidades de 22 e 45 metros. Através das figuras $4,5,6$ e 7 , pode-se observar que a termoclina inicia sua formação em outubro, encontrando-se presente na região até março, exceto nas estações mais rasas (C1 e C7), onde já neste mês ocorre a homogeneização da temperatura na coluna d'água, observada nas estações mais profundas (C3 e C9) apenas em maio. Nas quatro estações, assim como observado nas estações centrais dos dois bancos (estações 3 e TM), a termoclina atingiu seu máximo desenvolvimento em fevereiro. Já a salinidade apresentou-se totalmente homogênea na coluna d'água apenas em março e maio, enquanto nos demais meses observou-se os menores valores em profundidades menores, porém, com diferenças nunca superiores a 2 entre superfície e fundo (Figs. 4, 5, 6 e 7).

Os dados brutos referentes às concentrações dos nutrientes inorgânicos dissolvidos, bem como de clorofila-a e feofitina podem ser consultados no Anexo 1. As concentrações de fosfato variaram de 0,22 a $1,04 \mathrm{mM}$ na estação 3, e entre 0,20 e 1,53 mM na estação TM, sendo os maiores valores geralmente registrados em profundidades maiores que 20 metros e entre agosto e setembro/96 e entre novembro/96 e maio/97 na primeria área, e entre junho e agosto/96 e dezembro/96 e fevereiro/97 na segunda área (Figs. 8 e 9). 0 silicato apresentou uma padrão menos definido de variação tanto temporal como 
PEZZUTO et al.: Projeto Vieira: Cruzeiros IV a XIV.

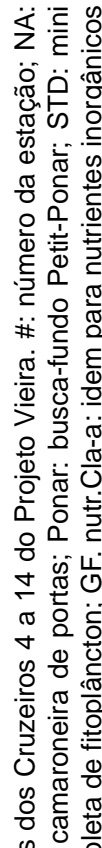

\⿻

ర్ల్

क⿺ 증

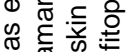

ส

중 웡 $\frac{0}{0}$

뜌

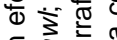

ह

ฐ્శ

을 क

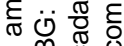

0

잉 휴

을는 은

( ) ह

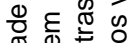

응 융 원

귱ํㅡㅇ 웅

으은윤

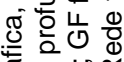

(

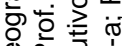

कूष

떵 옹응

ऽ స है

$\therefore$

ㄱㅇㅇㅇ응 응

뜬 융 응

잉

은

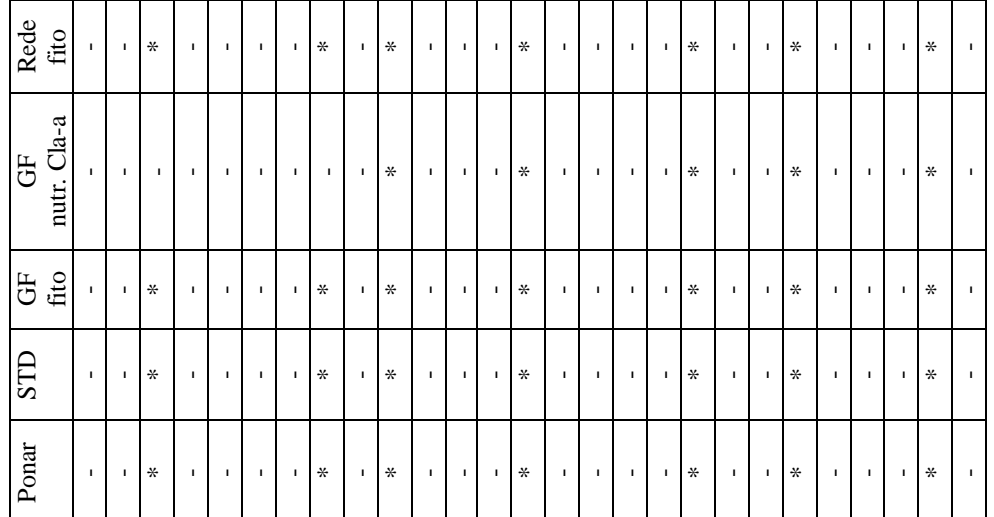

\section{를}

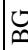

茩

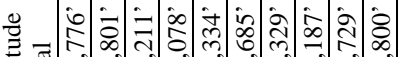

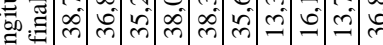

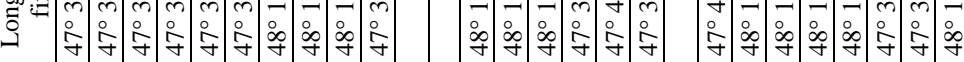

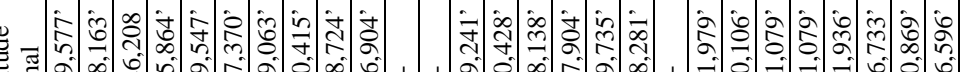

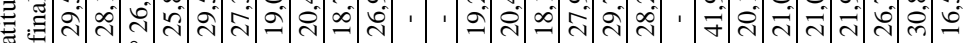
ـ

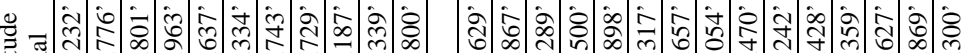

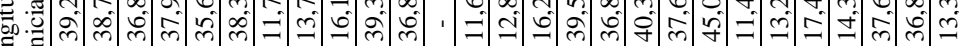

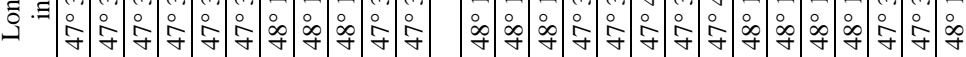

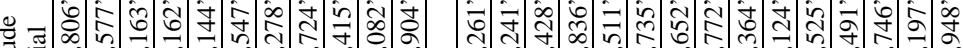

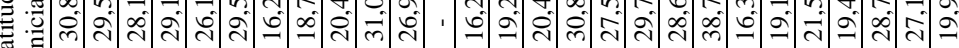

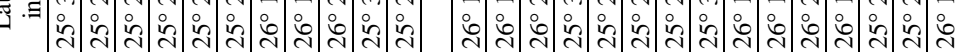

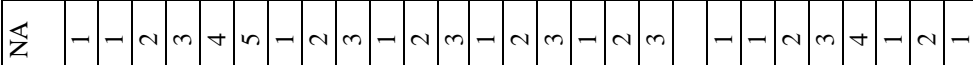

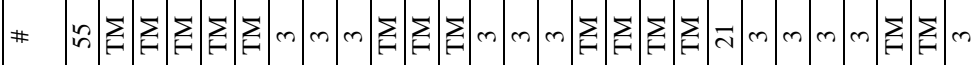

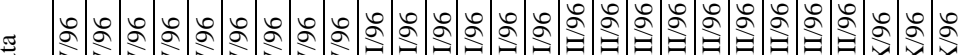

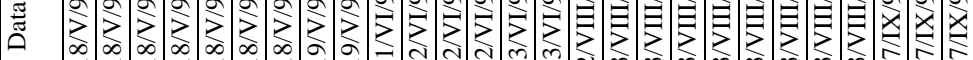

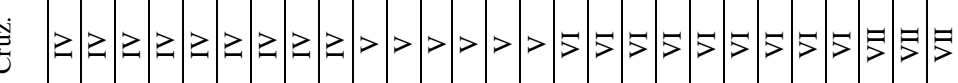




\begin{tabular}{|c|c|c|c|c|c|c|c|c|c|c|c|c|c|c|c|c|c|c|c|c|c|c|c|c|c|}
\hline$\underset{\widetilde{Q}}{ }$ & & * & & . & 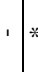 & & & $1 *$ & * & 1 & 1 & & $*$ & & & & & & & & ' & & * & & \\
\hline 吾 & & & & & 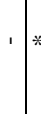 & & & $1 \%$ & * & 1 & & & $\because$ & & & & 1 & & & & ' & & * & & \\
\hline$\frac{5}{U}$ & & * & ' & ' & 1. & & ' & $1=$ & * & 1 & 1 & . & $\Rightarrow$ & 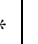 & ' & I & 1 & ' & & ' & ' & & * & & \\
\hline & & * & & & 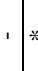 & 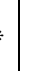 & & $1=$ & * & $*$ & & * & $*$ & * & & $*$ & 1 & $=$ & & ' & . & & * & * & \\
\hline 5 & & * & 1 & & $1 *$ & 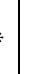 & & 1 . & * & $*$ & .1 & 1 & $*$ & 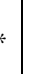 & $\begin{array}{lll}1 & 1\end{array}$ & 1 & 1 & & ' & ' & ' & & * & & ' \\
\hline है & & 1 & & & ' & ' & & ' & & $*$ & $*$ & $* *$ & * * & * & & $*$ & $*$ & $*$ & & ' & ' & & * & & $*$ \\
\hline & $*$ & * & $*$ & $*$ & * & * & * & $* *$ & * & . &. & . & & 1 . & * & & . & . & $*$ & * & * & * & ' & & \\
\hline & $\widehat{m}$ & & & el: & & 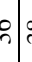 & $\infty$ & $\stackrel{\infty}{\infty}$ & $\infty$ & તે & & $\forall$ & $m \simeq$ & & $\mathrm{m}$ & $\mathscr{F}$ & $q$ & & $\vec{v}$ & $\ddot{m}$ & 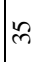 & m & & & \\
\hline 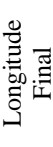 & 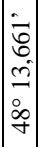 & 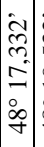 & 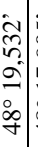 & 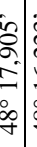 & 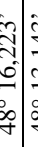 & 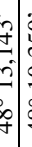 & 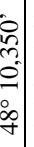 & 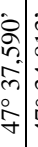 & 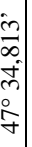 & $\begin{array}{c}\dot{q} \\
\vdots \\
0 \\
i \\
0 \\
o \\
+\end{array}$ & 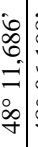 & 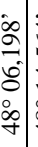 & 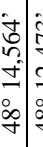 & 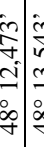 & 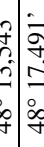 & 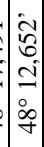 & 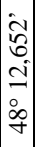 & 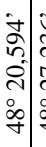 & 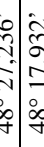 & 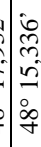 & 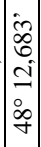 & 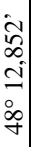 & $\stackrel{\circ}{\circ}$ & & 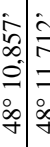 \\
\hline 䔍 & 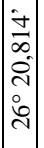 & 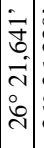 & 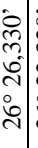 & 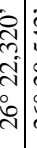 & 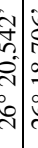 & 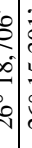 & 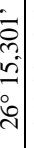 & $\begin{array}{l}i \\
0 \\
0 \\
0 \\
0 \\
0 \\
0 \\
\\
\end{array}$ & 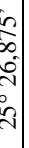 & 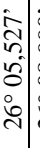 & 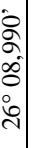 & 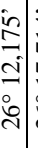 & 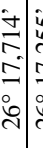 & & 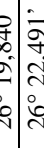 & 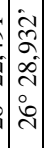 & 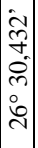 & 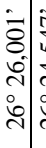 & 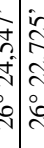 & $\begin{array}{l}0 \\
\vdots \\
0 \\
0 \\
0 \\
0\end{array}$ & 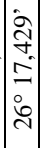 & 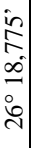 & $\begin{array}{l}0 \\
0 \\
0\end{array}$ & 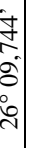 & 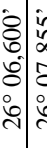 \\
\hline 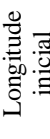 & 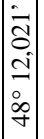 & {$\left[\begin{array}{c}1 \\
0 \\
m \\
2 \\
\infty \\
\infty \\
+\end{array}\right.$} & & 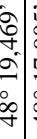 & 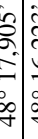 & 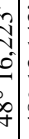 & 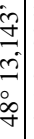 & 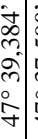 & 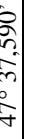 & 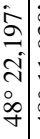 & 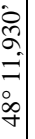 & 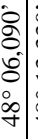 & 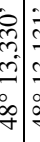 & & 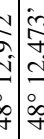 & 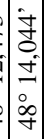 & 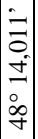 & 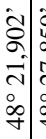 & 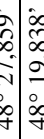 & 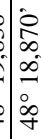 & 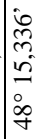 & 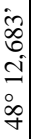 & $\stackrel{1}{2}$ & 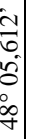 & $\begin{array}{l}\hat{\hat{a}} \\
\vdots \\
= \\
o \\
o \\
o\end{array}$ \\
\hline 总 & 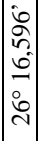 & 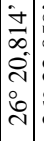 & 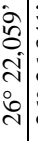 & 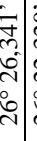 & 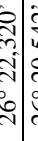 & 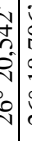 & 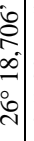 & 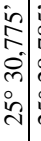 & 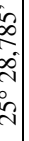 & 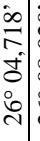 & 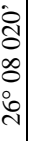 & 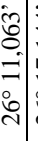 & 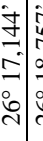 & 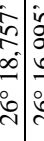 & 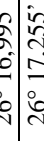 & 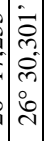 & $\mid$ & 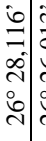 & 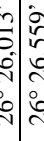 & 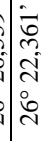 & 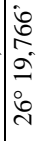 & 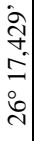 & $\begin{array}{c}1 \\
\delta \\
\vdots \\
\vdots \\
0 \\
0 \\
0\end{array}$ & & 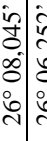 \\
\hline & $\mathrm{N}$ & $m$. & $\nabla$. & - & ○ & $v$. & $m$. & - & v & & & & & & $-\sim$ & - & $N$ & & - & $N$ & $m$ & ナ & & & \\
\hline & $m$ & & m. & $m$ & $m s$ & n & $m$ & $\sum_{i}$ & $\sum$ & 己| & & $\tilde{c}$ & オீ. & $m$ & $n m$ & 8 & 8 & ర) & $\hat{\jmath}$ & $m$ & & & & & ల \\
\hline & $\mid$ & 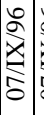 & 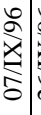 & 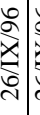 & 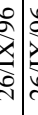 & & 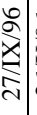 & : & L & 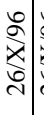 & 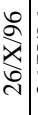 & & & & 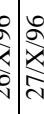 & 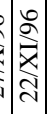 & 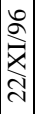 & 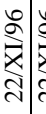 & 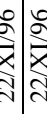 & 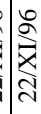 & 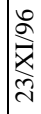 & $\begin{array}{l}\stackrel{2}{2} \\
\end{array}$ & & & \\
\hline & & & & & & & & & & & & & & & & & & & & & & & & & \\
\hline
\end{tabular}




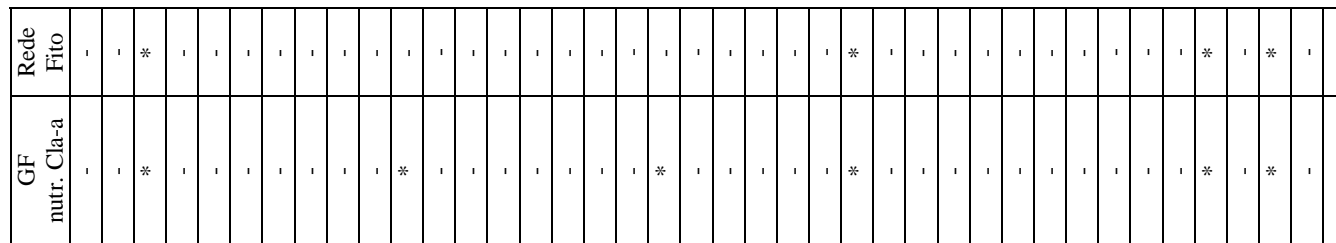

㠿彭

会

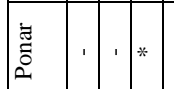

$\simeq$ 窎

ט

苛

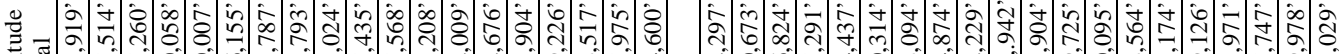

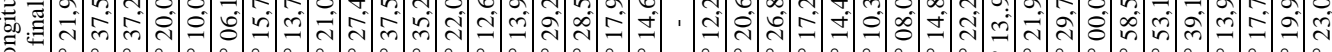
○一

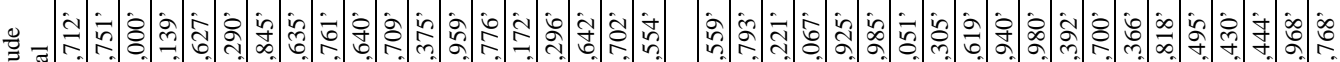

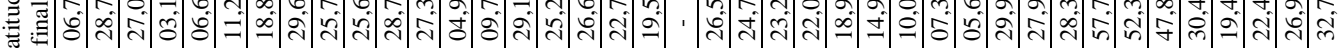

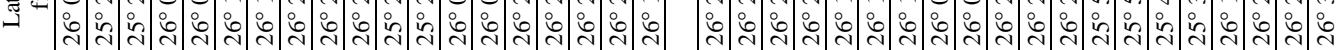

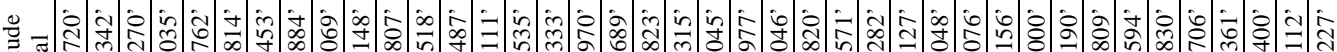

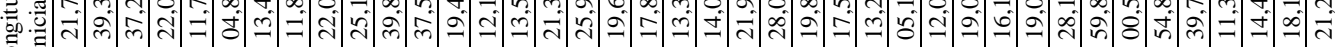

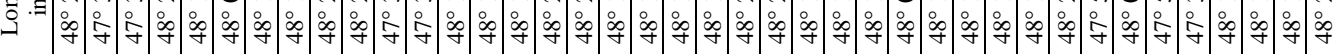

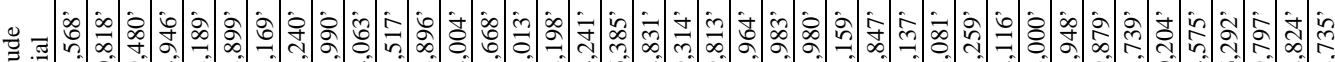

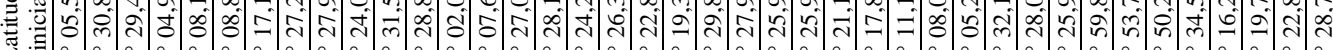

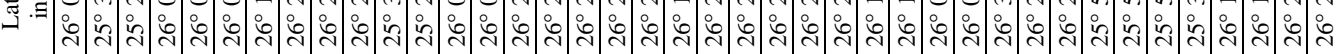

$\varangle$ $-2+\frac{2}{2}$

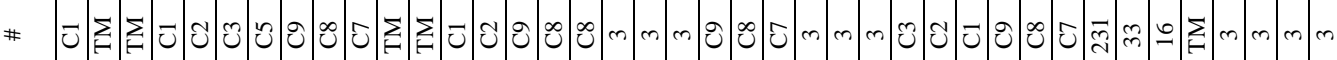

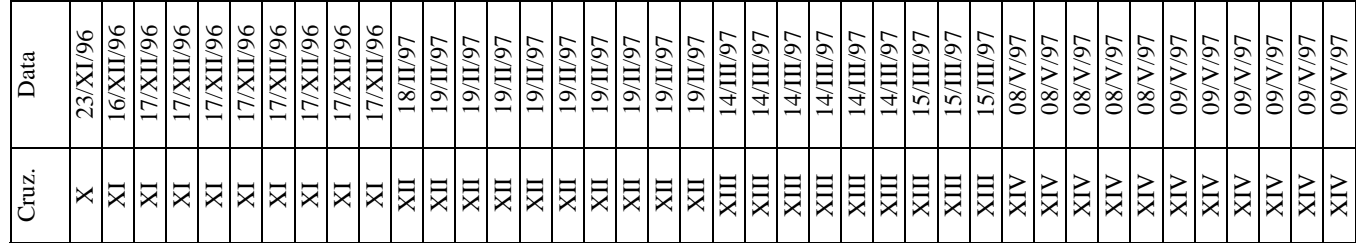



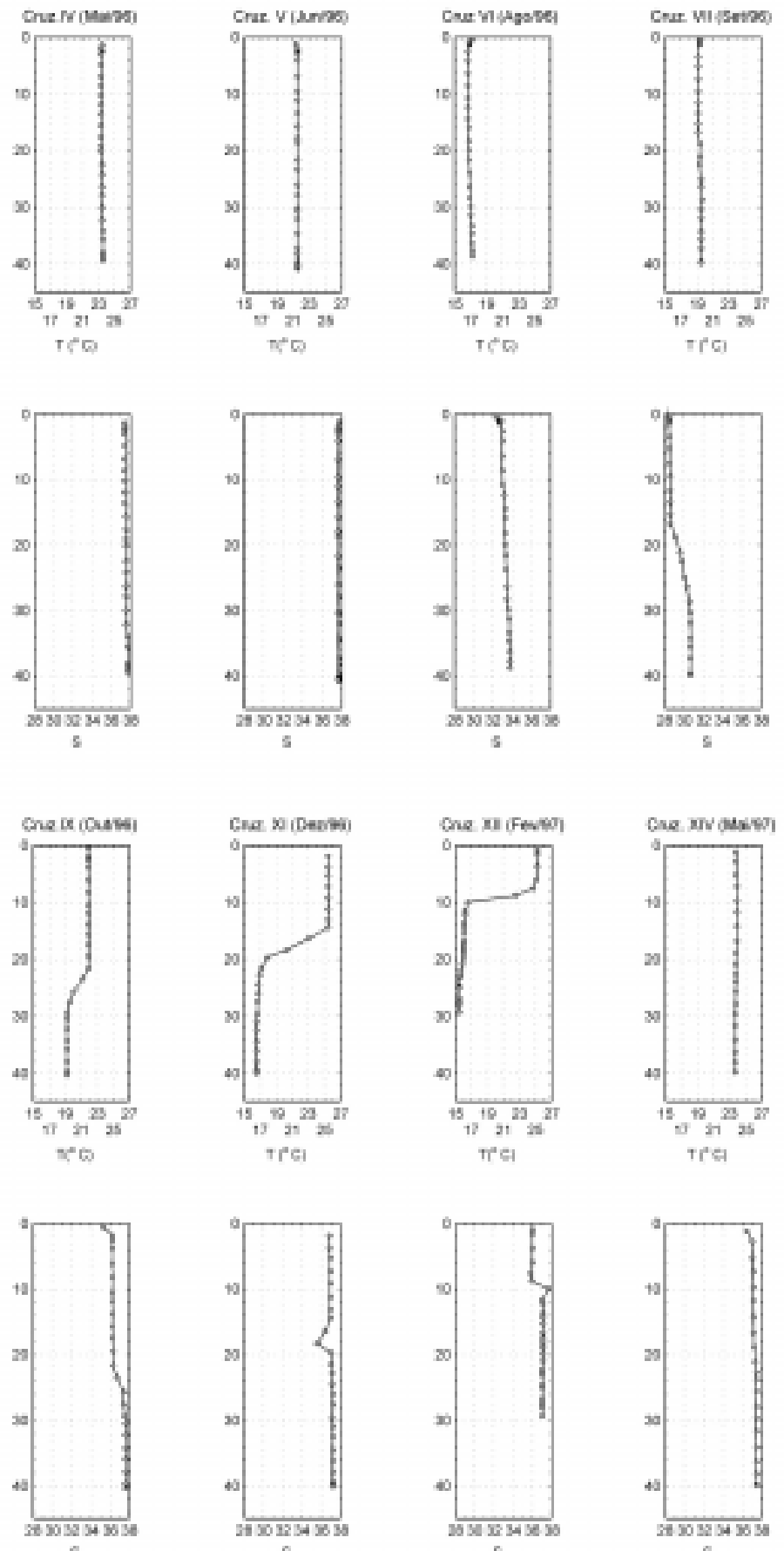

5

Figura 2. Perfis verticais de temperatura $\left(T^{\circ} \mathrm{C}\right)$ e salinidade $(\mathrm{S})$ da água obtidos na estação $\mathrm{TM}$, durante os Cruzeiros 4 a 14. 
PEZZUTO et al.: Projeto Vieira: Cruzeiros IV a XIV.
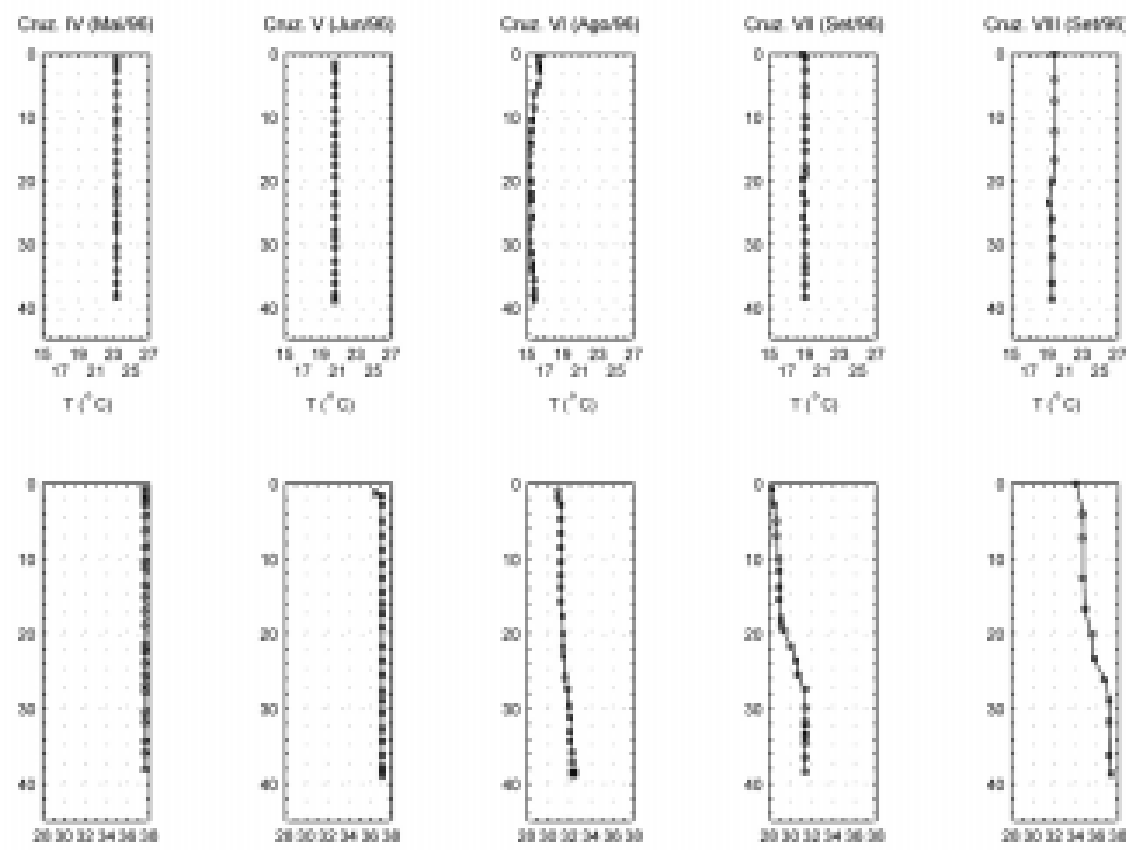

5
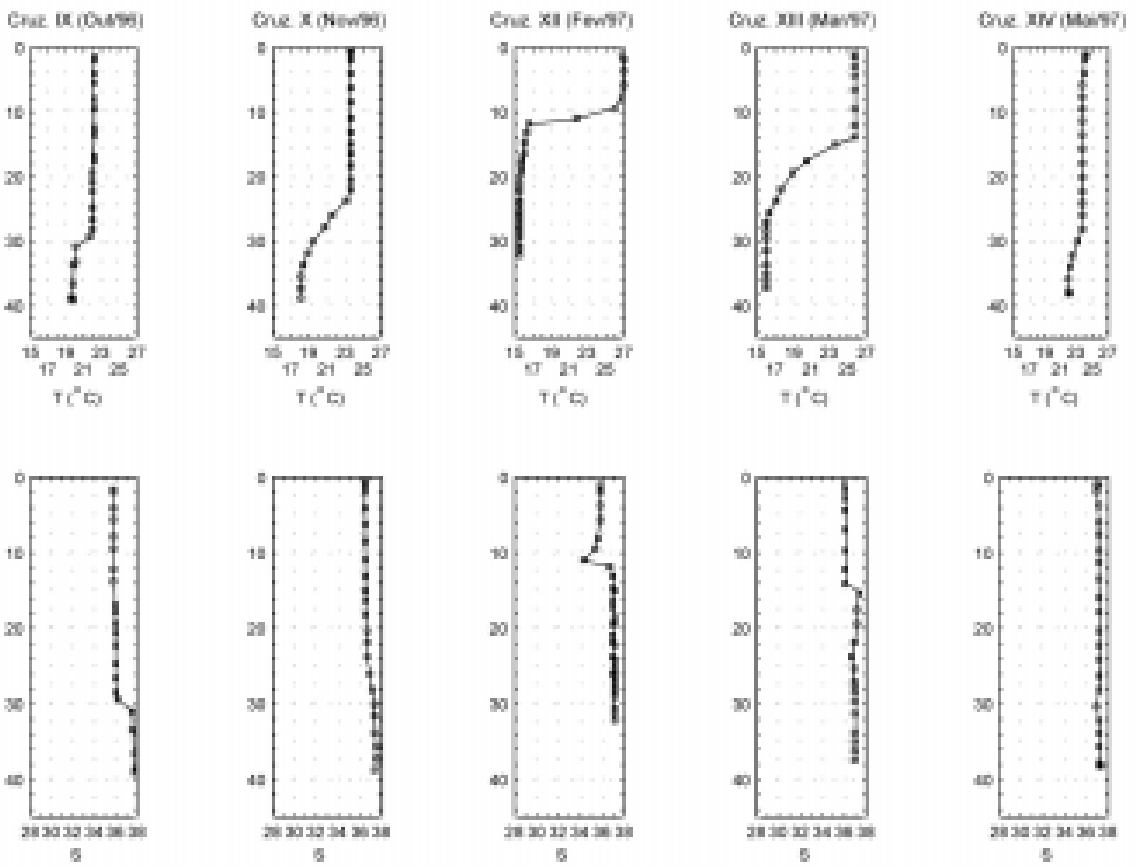

Figura 3. Perfis verticais de temperatura $\left(\mathrm{T}^{\circ} \mathrm{C}\right)$ e salinidade $(\mathrm{S})$ da água obtidos na estação 3 durante os Cruzeiros 4 a 14. 

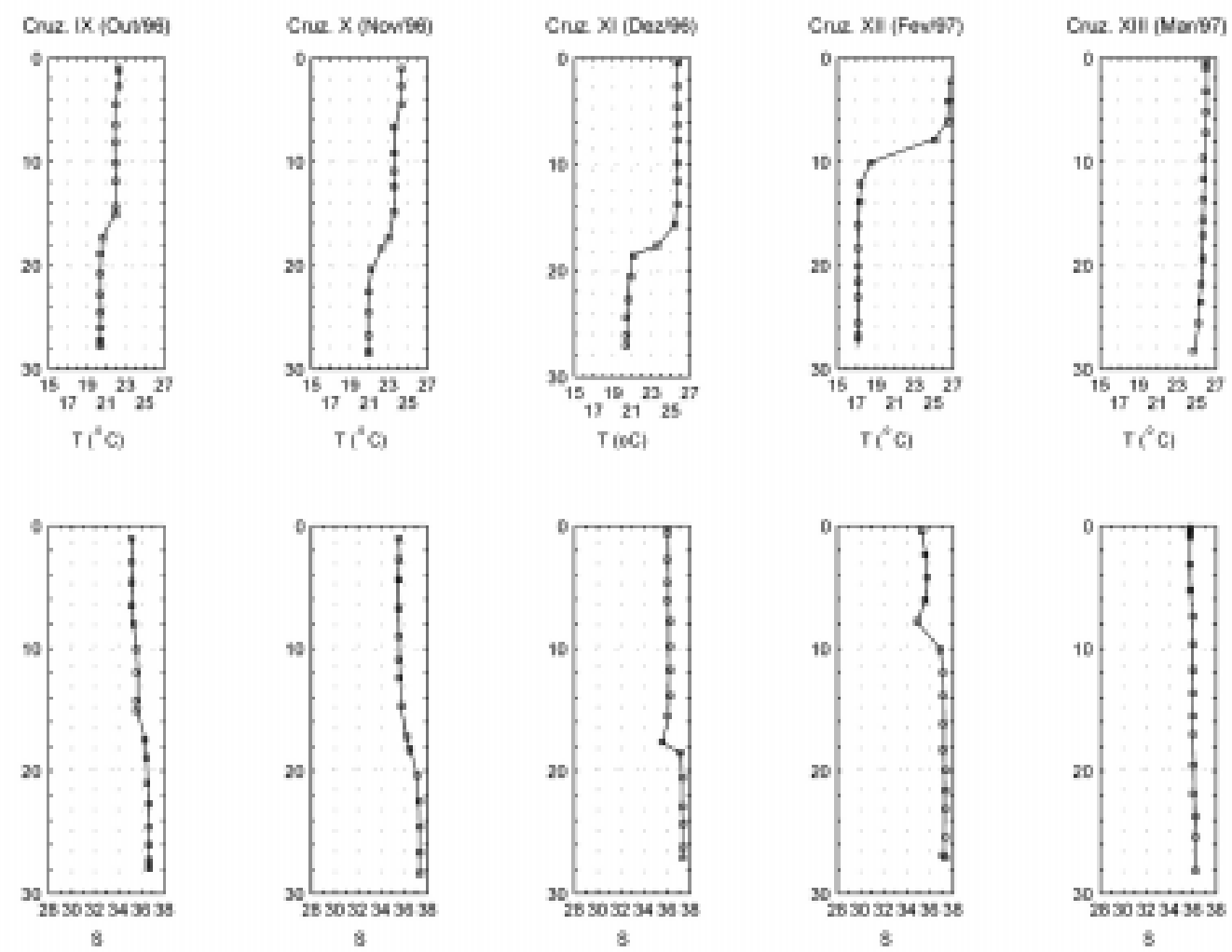

Figura 4. Perfis verticais de temperatura $\left(\mathrm{T}^{\circ} \mathrm{C}\right)$ e salinidade $(\mathrm{S})$ da água obtidos na estação $\mathrm{C} 1$ durante os Cruzeiros 9 a 13.

batimétrica em ambas as estações, atingindo valores entre 0,80 e 20,44 mM na estação 3 e entre 1,39 e $18,53 \mathrm{mM}$ na estação TM. Por outro lado, nitrito e nitrato apresentaram um claro aumento com a profundidade, exceto em outubro, quando valores mais elevados de nitrito foram observados em águas mais superfíciais. Para ambos os nutrientes, as maiores concentrações ocorreram entre setembro/96 e fevereiro/97. Já a clorofila-a mostrou uma ocorrência fortemente sazonal, com os maiores valores predominando no verão e em profundidades superiores a 25 metros em ambas as estações. Na estação 3 suas concentrações variaram entre 0,11 e $10,10 \mathrm{mg} / \mathrm{l}$, enquanto na TM foram observadas concentrações entre 0,27 e 11,48 mg/l (Figs. 8 e 9).
As análises efetuadas sobre os sedimentos coletados nas duas estações mostram a ocorrência de poucas variações temporais nas suas características granulométricas (Tabela 3). A estação 3 apresentou valores maiores de média e menores de desvio em relação à estação TM. Os diâmetros médios situaram-se entre 2,7 e 3,2 $\mathrm{f}$ (areias finas a muito finas), e os teores de areia foram sempre superiores a $92 \%$ em todas as amostragens. Embora os teores de matéria orgânica e carbonato de cálcio tenham sido similares nas duas estações, foram observadas variações temporais significativas nestes parâmetros, com valores mais elevados de matéria orgânica ocorrendo entre a primavera e verão, contrariamente ao carbonato de cálcio, que apre- 

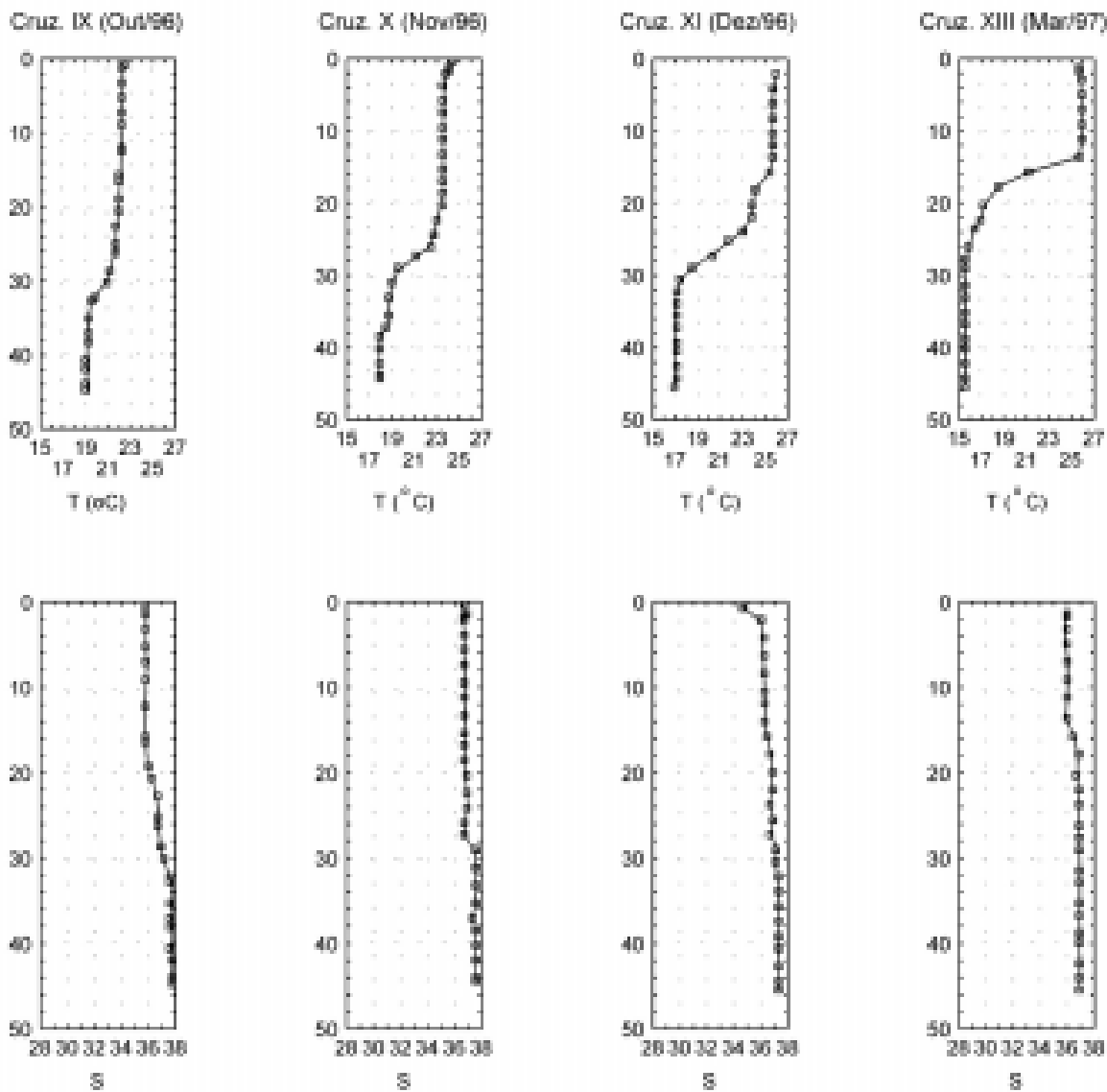

Figura 5. Perfis verticais de temperatura $\left(\mathrm{T}^{\circ} \mathrm{C}\right)$ e salinidade $(\mathrm{S})$ da água obtidos na estação C3 durante os Cruzeiros 9 a 13.

sentou seus teores mais elevados durante o outono e inverno.

Através da Tabela 4 pode-se verificar que as capturas de vieira nos dois bancos mantiveram-se baixas ao longo de todo o período de estudo, atingindo valores máximos da ordem de 35 indivíduos por hora de arrasto. Estes rendimentos foram superados apenas nos dois últimos cruzeiros, e especialmente no Cruzeiro 14, quando um recrutamento significativamente mais forte que os observados em outras oportunidades elevaram substancialmente as capturas por arrasto, chegando-se a obter até 95 indivíduos por hora no Banco de São Francisco (estação 3). Além dos dois bancos tradicionalmente visitados ao lon- go do estudo, no Cruzeiro 14 foram amostradas também três outras estações localizadas a sudeste da Baía de Paranaguá (estações 231, 33 e 16) (Fig. 1). Estas amostragens tiveram o objetivo de checar a possível ocorrência de vieiras vivas na área, uma vez que em arrastos diurnos executados ao longo do Cruzeiro 1, estas estações forneceram quantidades expressivas de conchas destacadas da espécie (valvas individuais de indivíduos mortos, sem as partes moles) (Borzone \& Pezzuto, 1997). Conforme se observa na tabela 4 , os três pontos apresentaram os melhores rendimentos de todo o cruzeiro, chegando a valores de até 140 indivíduos por hora de arrasto, sendo que, assim como 

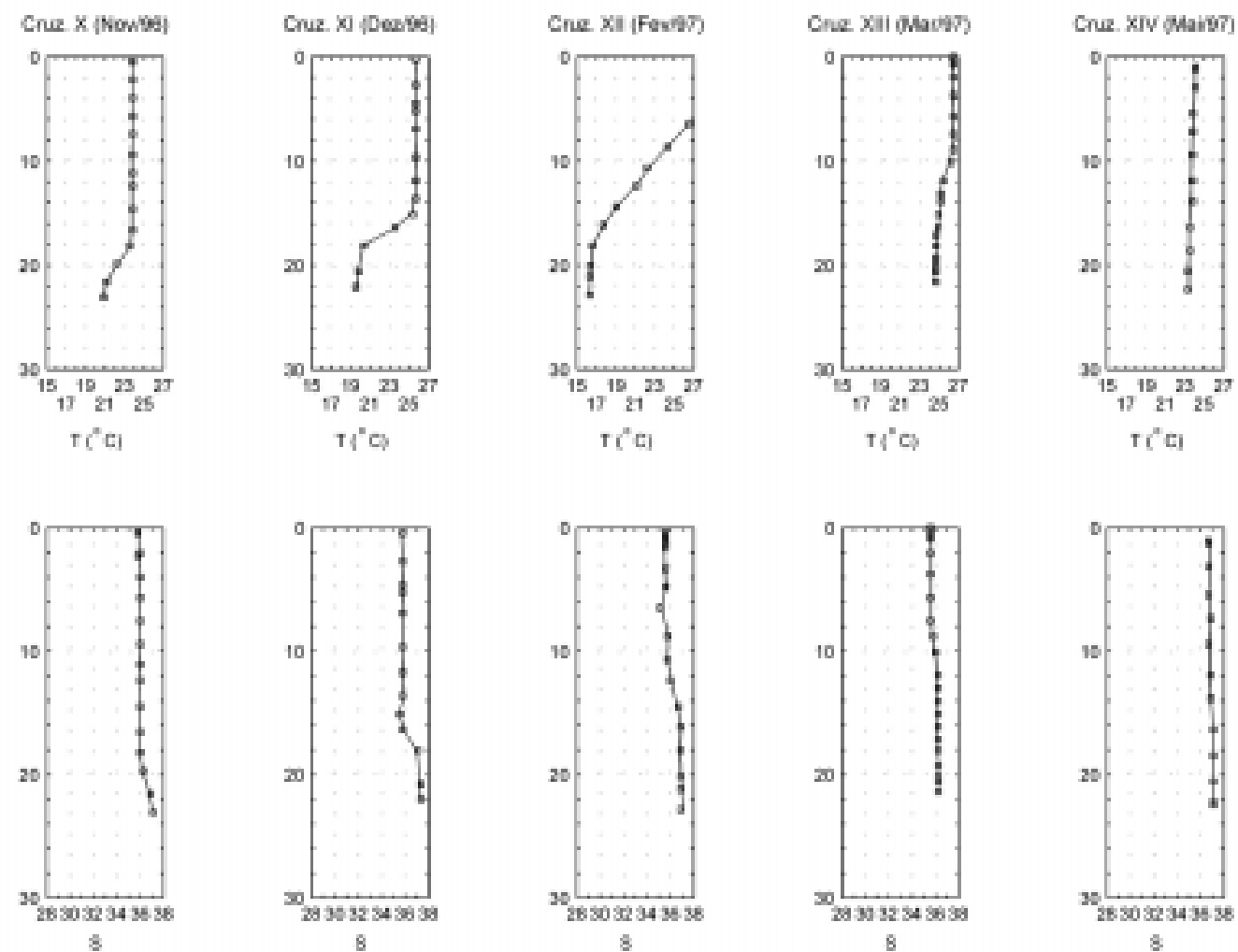

Figura 6. Perfis verticais de temperatura $\left(T^{\circ} \mathrm{C}\right)$ e salinidade $(\mathrm{S})$ da água obtidos na estação $\mathrm{C} 7$ durante os Cruzeiros 10 a 14.

nas demais estações, praticamente todos os organismos eram recrutas.

Também deve-se ressaltar que, seguindo a tendência observada ao longo dos três primeiros cruzeiros (Borzone \& Pezzuto, 1997; Pezzuto \& Borzone, 1997), houve um decréscimo contínuo e significativo nas capturas de vieiras no Banco do Bom Abrigo (estação TM), que variaram de 0 a 6 indivíduos por hora entre os Cruzeiros 5 e 12, indicando uma depleção total do banco (Tabela 4), o qual apresentou um sinal de recuperação somente no Cruzeiro 14, também em virtude do recrutamento já relatado.

As capturas de $C$. pubera vivas no Banco do Bom Abrigo, além de não terem nunca se igualado aos rendimentos observados durante o Cruzeiro 1 (Borzone \& Pezzuto, 1997), foram extremamente variáveis tanto entre cruzeiros, como entre arrastos sucessivos efetuados numa mesma saída, tendo atingindo valores entre 0 e 76 indivíduos por hora (Tabela 4).

\section{DISCUSSÃO}

As amostragens de coluna d'água efetuadas ao longo do projeto forneceram uma caracterização das condições oceanográficas da área ainda não registrada na literatura com a periodicidade e duração verificadas neste trabalho.

Uma das características mais importantes evidenciadas no período foi o fenômeno da formação da termoclina entre outubro e 

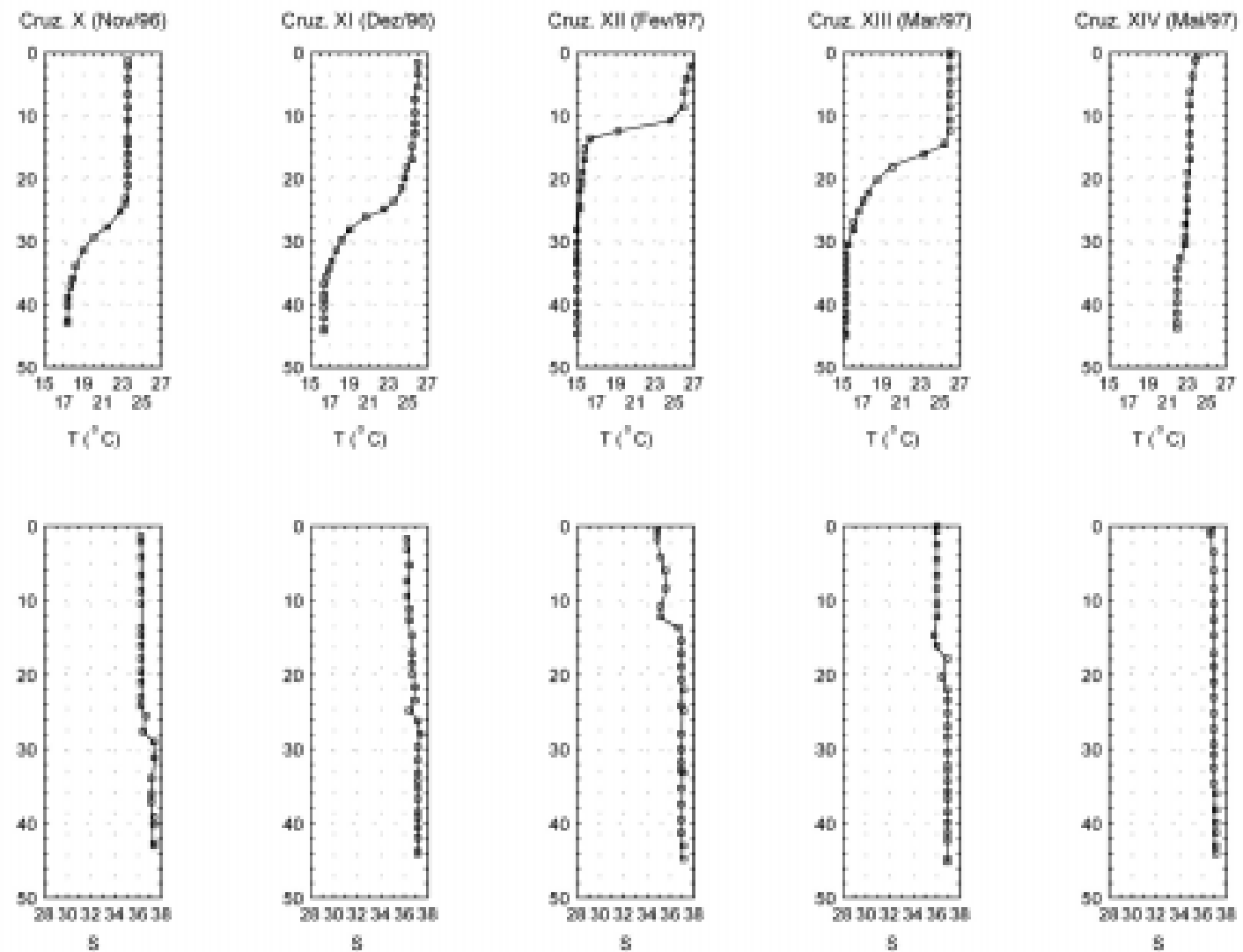

Figura 7. Perfis verticais de temperatura $\left(\mathrm{T}^{\circ} \mathrm{C}\right)$ e salinidade (S) da água obtidos na estação C9 durante os Cruzeiros 10 a 14.

abril. O resfriamento da água de fundo, reflete a intrusão da Água Central do Atlântico Sul (ACAS) sobre a plataforma continental, já relatada por diversos autores (p.ex. Matsuura, 1986; Campos et. al., 1996). A maioria dos trabalhos realizados anteriormente, embora abrangendo áreas variáveis entre os limites de Cabo Frio $\left(25^{\circ}\right)$ até o Cabo de Santa Marta Grande $\left(29^{\circ}\right)$, foram efetuados através de cruzeiros sazonais geralmente sob condições de inverno e verão, com poucas estações distribuídas a profundidades inferiores a 50 metros. Os resultados deste estudo sugerem que a penetração da ACAS é um fenômeno de grande escala que influencia regularmente toda a plataforma continental destas áreas até os vinte metros de profundidade.
As variações de temperatura observadas nos Bancos de São Francisco e Bom Abrigo, evidenciam que o sistema bentônico localizado pelo menos entre as isóbatas de 20 e 50 metros está sujeito a dois ciclos de aquecimento e resfriamento da água de fundo ao longo do ano. Analisando-se os dados apresentados neste relatório, em conjunto com aqueles constantes nos relatórios dos Cruzeiros 1 , 2 e 3 (Borzone \& Pezzuto, 1997; Pezzuto \& Borzone, 1997), observa-se que temperaturas mínimas de aproximadamente $16^{\circ} \mathrm{C}$ foram detectadas em fevereiro de 1996 e 1997, durante forte estratificação térmica devido à intrusão da ACAS sobre a plataforma interna, e em Julho de 1996, sob condições invernais de homogeneização da coluna d'água. Os 

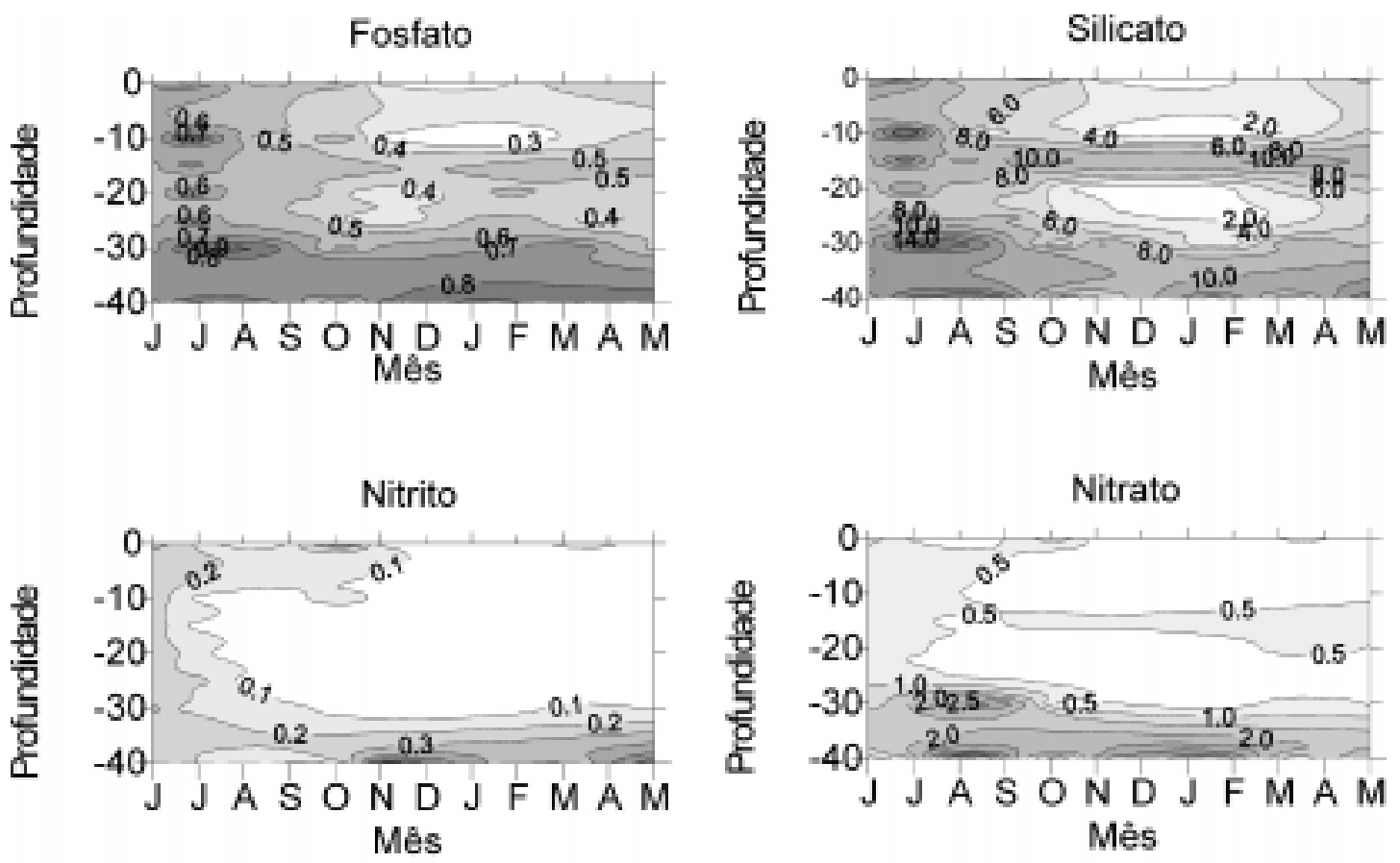

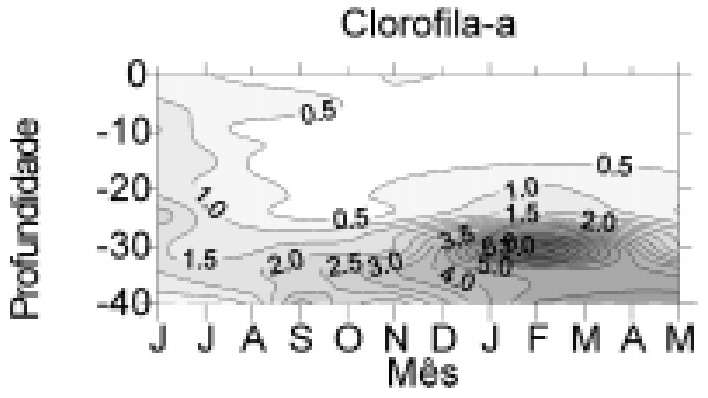

períodos de temperaturas mais elevadas foram observados em maio de 1996 e 1997, também com a homogeneização da coluna d'água ocorrida logo após a retração da ACAS, e em setembro e outubro de 1996, com o início do aquecimento da primavera, imediatamente antes de nova intrusão da ACAS sobre o fundo. Enquanto as temperaturas mínimas registradas no fundo atingiram praticamente o mesmo valor nos dois períodos do ano (inverno e verão), houve uma discrepância de cerca de $4^{\circ} \mathrm{C}$ nos valores das máximas tem-
Figura 8. Distribuição vertical das concentrações de fosfato, silicato, nitrito, nitrato e clorofila-a na estação 3 entre os Cruzeiros 5 e 14. Valores de clorofila-a expressos em $\mathrm{mg} / \mathrm{l}$. Demais valores em $\mathrm{mM}$.

peraturas, que foram mais elevadas no pico de outono em relação ao da primavera.

Coincidindo ainda com a entrada da ACAS sobre a plataforma interna, observouse um grande aumento das concentrações de clorofila-a junto ao fundo, precedido, na primavera, por um incremento de 8 vezes nos teores de matéria orgânica do sedimento. Embora a relação destas características oceanográficas com os estoques de vieira e $C$. pubera ainda devam ser investigadas nas próximas fases do projeto, é provável que elas 


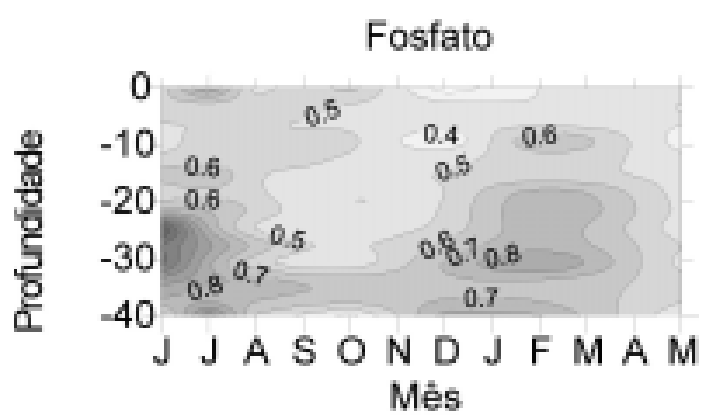

Nitrito
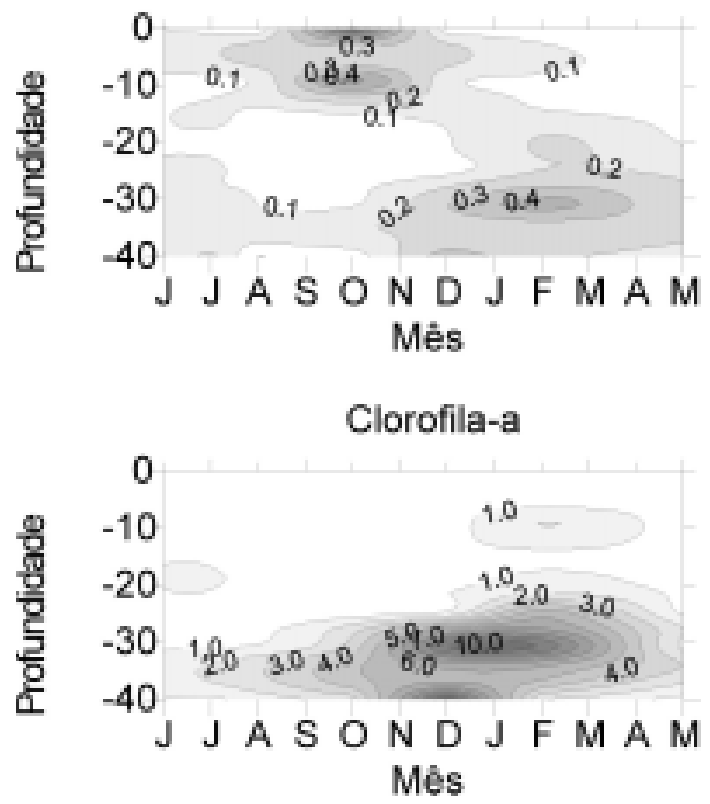

exerçam forte influência não só na distribuição dos dois recursos, como também em elementos de sua dinâmica populacional, como épocas e intensidade da atividade reprodutiva e taxas de crescimento.

Os sucessivos ajustes promovidos no beam-trawl a partir do quarto cruzeiro levaram às suas configurações finais (BG7, 8 e 9), cujas capturas de vieiras do Banco de São Francisco pareceram ter se mantido dentro de limites mais ou menos estáveis, considerando-se as variações de abundância intrínsecas da população devidas ao recrutamento e mor-
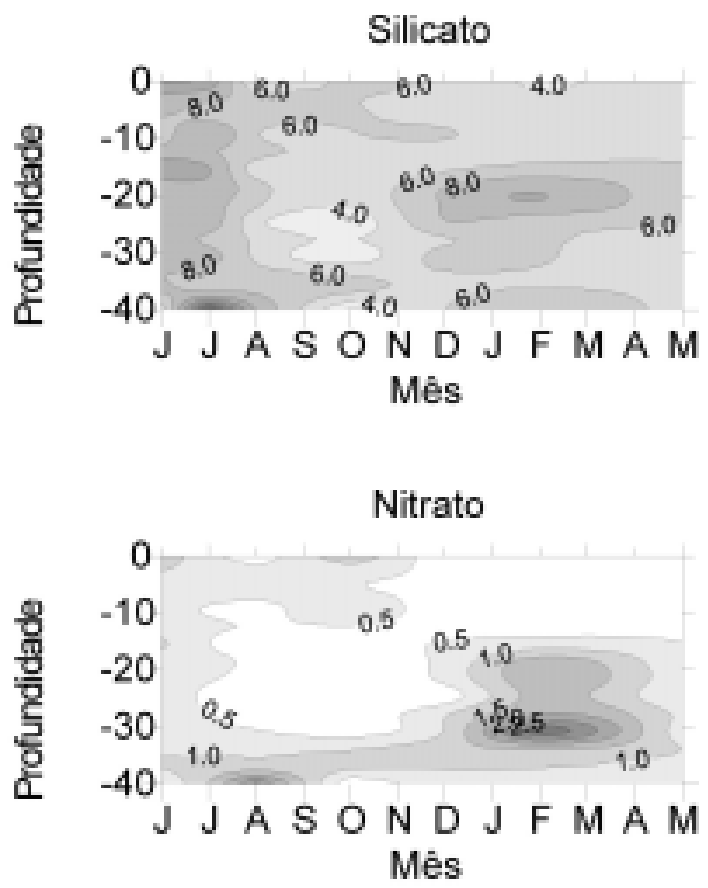

Figura 9. Distribuição vertical das concentrações de fosfato, silicato, nitrito, nitrato (em $\mathrm{mM}$ ) e clorofila-a (em $\mathrm{mg} / \mathrm{l})$ na estação TM entre os Cruzeiros 5 e 14. Profundidade em metros.

talidade. Ao longo dos Cruzeiros 5 e 14, não foram observadas variações claramente não naturais nas taxas de captura de vieira como ocorrido nos três primeiros cruzeiros, quando modificações implementadas no instrumento promoveram quedas expressivas na sua eficiência. De qualquer modo os valores absolutos de captura de vieiras constantes nesse relatório devem ser considerados como aproximados, uma vez que os mesmos ainda serão padronizados de acordo com as alterações de eficiência de captura proporcionada pelos ajustes efetuados no beam trawl ao longo do trabalho (Pezzuto \& Borzone, em prep.). 
Tabela 3. Resultados das análises sedimentológicas por cruzeiro e por estação. Cruz.: número do cruzeiro; \#: número da estação; Md: média; D: grau de seleção; A: assimetria; Mn: mediana; CG: curtose gráfica: Casc.: cascalho; Cálcio: carbonato de cálcio; MO: matéria orgânica.

\begin{tabular}{ccccccccccccc}
\hline Cruz & $\#$ & $\begin{array}{c}\text { Md } \\
(\phi)\end{array}$ & $\begin{array}{c}\mathrm{D} \\
(\phi)\end{array}$ & $\begin{array}{c}\mathrm{A} \\
(\phi)\end{array}$ & $\begin{array}{c}\text { Mn } \\
(\phi)\end{array}$ & $\begin{array}{c}\text { CG } \\
(\phi)\end{array}$ & $\begin{array}{c}\text { Casc } \\
(\%)\end{array}$ & $\begin{array}{c}\text { Areia } \\
(\%)\end{array}$ & $\begin{array}{c}\text { Silte } \\
(\%)\end{array}$ & $\begin{array}{c}\text { Argila } \\
(\%)\end{array}$ & $\begin{array}{c}\text { Cálcio } \\
(\%)\end{array}$ & $\begin{array}{c}\text { MO } \\
(\%)\end{array}$ \\
\hline IV & 3 & 3,07 & 0,35 & $-0,114$ & 3,11 & 0,469 & 0,55 & 97,76 & 1,18 & 0,50 & 6,53 & 1,44 \\
IV & TM & 2,70 & 0,74 & $-0,032$ & 2,70 & 0,519 & 0,24 & 96,06 & 2,18 & 1,50 & 7,14 & 1,03 \\
V & 3 & 3,08 & 0,39 & $-0,044$ & 3,12 & 0,504 & 0,00 & 97,03 & 1,22 & 1,50 & 6,51 & 1,35 \\
V & TM & 2,74 & 0,75 & $-0,008$ & 2,73 & 0,506 & 0,08 & 96,39 & 3,27 & 0,50 & 7,81 & 1,38 \\
VI & 3 & 3,12 & 0,39 & $-0,077$ & 3,17 & 0,530 & 0,00 & 97,24 & 1,26 & 1,00 & 6,11 & 1,58 \\
VI & TM & 2,95 & 0,69 & $-0,076$ & 2,95 & 0,500 & 0,06 & 98,88 & 1,07 & 0,00 & 7,32 & 1,00 \\
VII & 3 & 3,06 & 0,63 & $-0,361$ & 3,15 & 0,668 & 0,14 & 95,70 & 1,36 & 2,50 & 1,79 & 5,02 \\
VII & TM & 2,92 & 0,83 & 0,077 & 2,93 & 0,590 & 0,03 & 94,19 & 3,38 & 2,50 & 1,97 & 3,72 \\
VIII & 3 & 3,05 & 0,49 & $-0,099$ & 3,09 & 0,571 & 0,29 & 94,91 & 2,30 & 2,50 & 1,99 & 8,57 \\
IX & 3 & 3,18 & 0,35 & $-0,075$ & 3,21 & 0,583 & 0,18 & 97,45 & 1,37 & 1,00 & 1,78 & 4,16 \\
IX & TM & 2,73 & 0,86 & $-0,066$ & 2,73 & 0,496 & 0,29 & 95,78 & 0,43 & 3,50 & 1,58 & 6,03 \\
X & 3 & 3,03 & 0,81 & 0,388 & 3,02 & 0,738 & 0,06 & 93,13 & 2,25 & 4,50 & 1,87 & 7,96 \\
XI & TM & 2,69 & 0,71 & $-0,018$ & 2,69 & 0,532 & 0,23 & 97,10 & 1,28 & 0,50 & 1,05 & 7,13 \\
XIII & 3 & 2,86 & 0,41 & 0,150 & 2,80 & 0,613 & 0,10 & 96,43 & 1,03 & 2,50 & 5,59 & - \\
XIV & 3 & 3,17 & 1,01 & 0,282 & 3,21 & 0,853 & 0,26 & 92,24 & 2,00 & 5,50 & 8,97 & 2,16 \\
XIV & TM & 2,60 & 1,14 & 0,179 & 2,61 & 0,667 & 0,38 & 94,62 & 1,00 & 3,50 & 9,48 & 1,17 \\
\hline \hline
\end{tabular}

Com relação a $C$. pubera, suas capturas apresentaram uma variabilidade bastante mais acentuada entre cruzeiros do que as de vieira, não tendo sido possível em momento algum obter-se os rendimentos registrados no Cruzeiro I (Borzone \& Pezzuto, 1997) com os ajustes estruturais efetuados no equipamento. Desta forma, para a realização de projetos mais específicos sobre o estoque deste bivalvo, ainda deverão ser efetuadas adaptações no beam-trawl para melhorar sua eficiência. Embora seja difícil estabelecer-se uma relação clara entre as variáveis, observações efetuadas nos cruzeiros indicam que as taxas de captura de $C$. pubera foram bastante influenciadas pela ocorrência de condições ruins de mar, o que também sugere a necessidade de promover melhorias no equipamento para melhor amostragem do recurso mesmo sob condições adversas.
Ainda no tocante aos rendimentos obtidos de vieira, deve-se ressaltar o estado extremamente frágil do estoque na região, evidenciado pelas quedas nas capturas observadas no Banco do Bom Abrigo, o qual foi praticamente exaurido entre dezembro de 1995 (Borzone \& Pezzuto, 1997) e maio de 1996. Considerando-se a falta de informações seguras sobre as capturas comerciais da espécie nos últimos anos, dado que as pequenas quantidades obtidas geralmente não são oficialmente declaradas pelos mestres ao IBAMA (Pezzuto, obs. pess.), torna-se difícil estabelecer se tal redução de abundância no Banco do Bom Abrigo esteve relacionada à mortalidade por pesca ou apenas a fenômenos naturais. Contudo, sugere-se que, baseando-se nos resultados complementares a serem obtidos no decorrer do projeto, medidas emergenciais sejam implementadas no senti- 
Tabela 4. Características dos arrastos e material de vieira e Chione pubera coletado expresso em número de indivíduos vivos (viva), cluckers (valvas de indivíduos mortos, sem as partes moles, porém ainda unidas pelo ligamento) (cluk) e destacadas (idem, porém com valvas separadas) (dest.). Cruz.: número do cruzeiro; \#: número da estação; n: número do arrasto; equi: equipamento e sua configuração (vide tabela 1); tempo: tempo de arrasto em minutos; dir. (direção do arrasto, indicada pela orientação geográfica); hora: horas e minutos do início do arrasto.

\begin{tabular}{|c|c|c|c|c|c|c|c|c|c|c|c|}
\hline & & \multicolumn{5}{|c|}{ Arrasto } & \multicolumn{3}{|c|}{ Vieira } & \multicolumn{2}{|c|}{ Chione pubera } \\
\hline Cruz & $\#$ & $\mathrm{n}$ & equi & temp & dir. & hora & viva & cluk & dest & viva & cluk \\
\hline IV & 55 & 1 & BG 5 & 30 & $\mathrm{NE}$ & $1: 21$ & 2 & 0 & 24 & 1 & 41 \\
\hline IV & $\operatorname{tm} 1$ & 1 & BG 5 & 60 & $\mathrm{NE}$ & $2: 22$ & 13 & 0 & 60 & 30 & 183 \\
\hline IV & $\operatorname{tm} 1$ & 2 & BG 5 & 60 & $\mathrm{NE}$ & $3: 50$ & 8 & 0 & 20 & 3 & 81 \\
\hline IV & $\mathrm{tm} 1$ & 3 & BG 5 & 60 & $\mathrm{~N}$ & 11:11 & 0 & 0 & 108 & 26 & 106 \\
\hline IV & $\mathrm{tm} 1$ & 4 & BG 5 & 60 & SW & $13: 00$ & 0 & 1 & 32 & 11 & 100 \\
\hline IV & $\mathrm{tm} 1$ & 5 & BG 5 & 60 & $\mathrm{NE}$ & $14: 10$ & 2 & 0 & 63 & 21 & 180 \\
\hline IV & 3 & 1 & BG 5 & 60 & SW & $22: 10$ & 15 & 0 & 47 & - & - \\
\hline IV & 3 & 2 & BG 5 & 60 & SW & $0: 30$ & 19 & 6 & 48 & - & - \\
\hline IV & 3 & 3 & BG 5 & 60 & $\mathrm{NE}$ & $2: 20$ & 16 & 8 & 43 & - & - \\
\hline $\mathrm{V}$ & tm1 & 1 & BG 6 & 60 & $\mathrm{NE}$ & $23: 30$ & 2 & 0 & 38 & 36 & 54 \\
\hline $\mathrm{V}$ & $\mathrm{tm} 1$ & 2 & BG 6 & 60 & $\mathrm{NE}$ & $1: 00$ & 1 & 0 & 19 & 6 & 28 \\
\hline $\mathrm{V}$ & tm1 & 3 & BG 6 & 60 & $\mathrm{NE}$ & $2: 30$ & 3 & 0 & 35 & 7 & 39 \\
\hline V & 3 & 1 & BG 7 & 60 & SW & $22: 20$ & 34 & 1 & 67 & - & - \\
\hline $\mathrm{V}$ & 3 & 2 & BG 7 & 60 & SW & $0: 30$ & 9 & 2 & 25 & - & - \\
\hline $\mathrm{V}$ & 3 & 3 & BG 7 & 60 & $\mathrm{NE}$ & $2: 10$ & 21 & 1 & 35 & - & - \\
\hline $\mathrm{VI}$ & $\mathrm{tm} 1$ & 1 & BG 7 & 60 & $\mathrm{NE}$ & $23: 00$ & 3 & 0 & 16 & 25 & 63 \\
\hline $\mathrm{VI}$ & $\mathrm{tm} 1$ & 2 & BG 7 & 60 & SW & $0: 45$ & 2 & 0 & 23 & 56 & 101 \\
\hline VI & $\mathrm{tm} 1$ & 3 & BG 7 & 60 & $\mathrm{NE}$ & $2: 15$ & 2 & 1 & 25 & 71 & 60 \\
\hline VI & 21 & 1 & BG 7 & 60 & SW & $12: 45$ & 1 & 0 & 17 & 9 & 46 \\
\hline $\mathrm{VI}$ & 3 & 1 & BG 7 & 60 & SW & $18: 50$ & 14 & 1 & 39 & - & - \\
\hline VI & 3 & 2 & BG 7 & 60 & SW & $21: 00$ & 33 & 0 & 62 & - & - \\
\hline $\mathrm{VI}$ & 3 & 3 & BG 7 & 60 & $\mathrm{NE}$ & 22.30 & 19 & 0 & 57 & - & - \\
\hline VI & 3 & 4 & BG 7 & 60 & SW & $23: 40$ & 20 & 2 & 0 & - & - \\
\hline VII & tm1 & 1 & BG 7 & 60 & $\mathrm{NE}$ & $2: 30$ & 2 & 0 & 36 & 25 & 118 \\
\hline VII & tm1 & 2 & BG 8 & 60 & SW & $4: 30$ & 0 & 0 & 58 & 76 & 181 \\
\hline VII & 3 & 1 & BG 7 & 60 & SW & $20: 00$ & 13 & 1 & 58 & - & - \\
\hline VII & 3 & 2 & BG 8 & 60 & SW & $21: 20$ & 13 & 1 & 56 & - & - \\
\hline VII & 3 & 3 & BG 8 & 60 & SW & $22: 50$ & 15 & 2 & 62 & - & - \\
\hline VII & 3 & 4 & BG 8 & 60 & SW & $23: 50$ & 19 & 1 & 61 & - & - \\
\hline VIII & 3 & 1 & BG 8 & 60 & $\mathrm{NE}$ & $20: 20$ & 13 & 1 & 159 & - & - \\
\hline VIII & 3 & 2 & BG 8 & 60 & NE & $23: 00$ & 16 & 0 & 155 & - & - \\
\hline VIII & 3 & 3 & BG 8 & 60 & $\mathrm{NE}$ & $1: 20$ & 16 & 1 & 162 & - & - \\
\hline IX & $\mathrm{tm} 1$ & 1 & BG 8 & 60 & $\mathrm{NE}$ & $1: 00$ & 4 & 0 & 16 & 17 & 51 \\
\hline IX & $\mathrm{tm} 1$ & 2 & BG 8 & 60 & $\mathrm{NE}$ & $4: 00$ & 5 & 0 & 21 & 18 & 104 \\
\hline IX & 3 & & $\mathrm{RC}$ & 33 & $\mathrm{NE}$ & $21: 00$ & 1 & 0 & 0 & - & - \\
\hline IX & 3 & 1 & BG 8 & 60 & SW & $22: 00$ & 7 & 0 & 54 & - & - \\
\hline IX & 3 & 2 & BG 8 & 60 & SW & $0: 10$ & 35 & 5 & 87 & - & - \\
\hline $\mathrm{X}$ & 3 & 1 & BG 8 & 60 & $\mathrm{NE}$ & $20: 50$ & 8 & 0 & 61 & - & - \\
\hline$X$ & 3 & 2 & BG 8 & 60 & $\mathrm{NE}$ & $22: 10$ & 21 & 0 & 103 & - & - \\
\hline$X$ & 3 & 3 & BG 8 & 60 & $\mathrm{NE}$ & $0: 30$ & 11 & 0 & 90 & - & - \\
\hline $\mathrm{X}$ & 3 & 4 & BG 8 & 45 & NE/SW & $1: 30$ & 19 & 2 & 70 & - & - \\
\hline $\mathrm{XI}$ & tm1 & 1 & BG 8 & 60 & $\mathrm{NE}$ & $21: 40$ & 4 & 3 & 80 & 66 & 320 \\
\hline $\mathrm{XI}$ & $\mathrm{tm} 1$ & 2 & BG 8 & 60 & $\mathrm{~N}$ & $0: 00$ & 6 & 0 & 52 & 61 & 337 \\
\hline XII & $\mathrm{tm} 1$ & 1 & BG 9 & 65 & $\mathrm{NE}$ & $21: 40$ & 4 & 0 & 46 & 0 & 318 \\
\hline XII & $\mathrm{tm} 1$ & 2 & BG 9 & 60 & $\mathrm{NE}$ & $1: 10$ & 3 & 0 & 45 & 29 & 278 \\
\hline XII & 3 & 1 & BG 9 & 60 & $\mathrm{~N}$ & $20: 02$ & 33 & 0 & 59 & - & - \\
\hline XII & 3 & 2 & BG 9 & 60 & $\mathrm{NE}$ & $21: 15$ & 40 & 3 & 65 & - & - \\
\hline XII & 3 & 3 & BG 9 & 60 & $\mathrm{NE}$ & $23: 35$ & 10 & 0 & 49 & - & - \\
\hline XIII & 3 & 1 & BG 8 & 60 & $\mathrm{NE}$ & $19: 00$ & 32 & 2 & 49 & - & - \\
\hline XIII & 3 & 2 & BG 8 & 60 & $\mathrm{NE}$ & $20: 30$ & 18 & 1 & 52 & - & - \\
\hline XIII & 3 & 3 & BG 8 & 60 & $\mathrm{NE}$ & $23: 00$ & 40 & 3 & 62 & - & - \\
\hline XIV & 231 & 1 & BG 8 & 30 & $\mathrm{~N}$ & $22: 00$ & 55 & 0 & 89 & - & - \\
\hline XIV & 33 & 1 & BG 8 & 30 & $\mathrm{NE}$ & $23: 00$ & 44 & 0 & 74 & - & - \\
\hline XIV & 16 & 1 & BG 8 & 30 & $\mathrm{~N}$ & $1: 00$ & 70 & 1 & 78 & - & - \\
\hline XIV & tm1 & 1 & BG 8 & 60 & $\mathrm{NE}$ & $3: 00$ & 24 & 0 & 50 & 5 & 39 \\
\hline XIV & 3 & 1 & BG 8 & 60 & SW & $18: 50$ & 86 & 2 & 78 & - & - \\
\hline XIV & 3 & 2 & BG 8 & 60 & SW & $20: 15$ & 95 & 5 & 82 & - & - \\
\hline XIV & 3 & 3 & BG 8 & 60 & SW & $21: 30$ & 65 & 2 & 78 & - & - \\
\hline XIV & 3 & 4 & BG 8 & 60 & SW & $23: 00$ & 29 & 0 & 49 & - & - \\
\hline
\end{tabular}


do de evitar um possível colapso irreversível do recurso no sul do Brasil.

\section{AGRADECIMENTOS}

Os autores desejam expressar seus agradecimentos ao CEPSUL/IBAMA (SC) pelas facilidades oferecidas, à tripulação no N/ $\mathrm{Pq}$ Diadorim pela colaboração na realização dos cruzeiros, e aos colegas Gilberto Caetano Manzoni responsável pela área de Maricultura do CTTMAR pela montagem e orientação sobre os coletores de sementes, e Ewerton Wegner e Frederico César Leal Rodrigues, responsáveis pelas atividades subaquáticas do CTTMAR, pelo auxílio no mergulho para instalação das estruturas na Ilha da Figueira.

\section{REFERÊNCIAS BIBLIOGRÁFICAS}

Arar, E. J. \& G. B. Collins, 1992. In vitro determination of chlorophyll-a and phaeophytin-a in marine and freshwater phytoplankton by fluorescence. USEPA Methods for the determination of chemical substances in marine and estuarine environmental samples, EPA, Washington, Reprint Turner Designs, 2/93, $16 \mathrm{pp}$.

Borzone, C. A. \& P. R. Pezzuto. 1997. Relatório Técnico dos Cruzeiros do Projeto Vieira. I. Cruzeiro I (4 a 9 de dezembro de 1995). Notas Técnicas da FACIMAR, 1:67-79.

Campos, E. J. D.; Ikeda, Y.; Castro, B. M.; Gaeta, S. A.; Lorenzetti, J. A. \& M. R. Ste. 1996. Experiment studies circulation in the Western South Atlantic. Eos, Transactions, American Geophysical Union, 77(27): 253259.

Grasshoff, K; Ehrhardt, M. \& K. Krenuling. 1983. Methods of seawater analysis. Verlay Chenie, Germany, 419 pp.

Matsuura, Y. 1986. Contribuição ao estudo da estrutura oceanográfica da região sudeste entre Cabo Frio (RJ) e Cabo de Santa Marta Grande (SC). Ciência e Cultura, 38(8): 1439-1450.

Parsons, T. R.; Maita, Y. \& C. M. Lalli, 1984. A manual of chemical and biological methods for seawater analysis. Pergamon Press, Oxford, 173pp.

Pezzuto, P. R. \& C. A. Borzone. 1997. Relatório Técnico dos Cruzeiros do Projeto Vieira. II. Cruzeiros II (15 a 17 de março de 1996) e III (20 a 22 de abril de 1996). Notas Técnicas da FACIMAR, 1:81-88. 
ANEXO 1. Dados brutos referentes às concentrações de Fosfato, Silicato, Nitrito, Nitrato, Clorofila-a (Cla-a) e Feofitina (Feof.) observadas nas estações 3 e TM em diferentes cruzeiros e profundidades.

\begin{tabular}{|c|c|c|c|c|c|c|c|c|c|c|c|c|c|}
\hline \multirow[b]{2}{*}{ Cruzeiro } & \multirow[b]{2}{*}{$\begin{array}{c}\text { Prof. } \\
(\mathrm{m})\end{array}$} & \multicolumn{6}{|c|}{ Banco São Francisco (\#3) } & \multicolumn{6}{|c|}{ Banco Bom Abrigo (\#TM) } \\
\hline & & $\begin{array}{c}\mathrm{PO}_{4} \\
(\mu \mathrm{M})\end{array}$ & $\begin{array}{c}\mathrm{Si}(\mathrm{OH})_{4} \\
(\mu \mathrm{M})\end{array}$ & $\begin{array}{l}\mathrm{NO}_{2} \\
(\mu \mathrm{M})\end{array}$ & $\begin{array}{l}\mathrm{NO}_{3} \\
(\mu \mathrm{M})\end{array}$ & $\begin{array}{l}\text { Cla-a } \\
(\mu \mathrm{g} / \mathrm{l})\end{array}$ & $\begin{array}{c}\text { Feo } \\
(\mu \mathrm{g} / \mathrm{l})\end{array}$ & $\begin{array}{c}\mathrm{PO}_{4} \\
(\mu \mathrm{M})\end{array}$ & $\begin{array}{c}\mathrm{Si}(\mathrm{OH})_{4} \\
(\mu \mathrm{M})\end{array}$ & $\begin{array}{l}\mathrm{NO}_{2} \\
(\mu \mathrm{M})\end{array}$ & $\begin{array}{l}\mathrm{NO}_{3} \\
(\mu \mathrm{M})\end{array}$ & $\begin{array}{l}\text { Cla-a } \\
(\mu \mathrm{g} / \mathrm{l})\end{array}$ & $\begin{array}{c}\text { Feo } \\
(\mu \mathrm{g} / \mathrm{l})\end{array}$ \\
\hline \multirow{7}{*}{5} & 0 & 0,68 & 12,78 & 0,37 & 1,37 & 1,01 & 0,36 & 0,56 & 12,35 & 0,10 & 1,35 & 0,90 & 0,27 \\
\hline & 10 & 0,57 & 9,57 & 0,31 & 0,70 & 1,90 & 0,33 & 0,33 & 5,03 & 0,07 & 0,70 & 0,52 & 0,33 \\
\hline & 15 & 0,54 & 7,97 & 0,31 & 0,73 & 1,36 & 0,26 & 0,62 & 12,19 & 0,09 & 1,20 & 0,93 & 0,33 \\
\hline & 20 & 0,46 & 5,03 & 0,29 & 0,52 & 1,74 & 0,29 & 0,38 & 4,82 & 0,08 & 0,52 & 0,88 & 0,32 \\
\hline & 25 & 0,48 & 5,78 & 0,23 & 0,68 & 2,52 & 0,21 & 1,53 & 8,93 & 0,12 & 0,88 & 0,90 & 0,49 \\
\hline & 30 & 0,62 & 9,94 & 0,36 & 1,02 & 1,83 & 0,05 & 1,44 & 9,89 & 0,12 & 1,01 & 0,75 & 0,32 \\
\hline & 40 & 0,64 & 10,16 & 0,28 & 0,87 & 0,63 & 0,24 & 0,53 & 4,71 & 0,09 & 0,48 & 1,00 & 0,58 \\
\hline \multirow{7}{*}{6} & 0 & 0,85 & 14,42 & 0,18 & 0,33 & 0,53 & 0,11 & 0,92 & 11,85 & 0,06 & 0,63 & 0,59 & 0,21 \\
\hline & 10 & 1,04 & 20,44 & 0,05 & 1,04 & 0,54 & 0,15 & 0,74 & 14,69 & 0,03 & 0,41 & 0,84 & 0,36 \\
\hline & 15 & 0,81 & 17,87 & 0,03 & 0,85 & 1,34 & 0,46 & 0,74 & 11,24 & 0,16 & 0,43 & 0,99 & 0,32 \\
\hline & 20 & 0,85 & 14,91 & 0,14 & 0,80 & 0,54 & 0,16 & 0,94 & 18,53 & 0,16 & 1,13 & 2,19 & 0,44 \\
\hline & 25 & 0,88 & 13,82 & 0,29 & 0,96 & 1,23 & 0,39 & 0,75 & 10,31 & 0,15 & 0,36 & 0,62 & 0,46 \\
\hline & 30 & 0,97 & 19,57 & 0,11 & 2,13 & 0,70 & 0,19 & 0,73 & 10,64 & 0,26 & 0,51 & 0,72 & 0,19 \\
\hline & 40 & 0,96 & 17,27 & 0,20 & 1,40 & 0,56 & 0,12 & 1,09 & 19,24 & 0,24 & 1,53 & 0,76 & 0,20 \\
\hline \multirow{7}{*}{7} & 0 & 0,45 & 4,17 & 0,02 & 0,10 & 0,28 & 0,04 & 0,46 & 3,58 & 0,02 & 0,19 & 0,31 & 0,14 \\
\hline & 10 & 0,48 & 3,70 & 0,02 & 0,52 & 0,11 & 0,02 & 0,46 & 3,52 & 0,01 & 0,14 & 0,37 & 0,09 \\
\hline & 15 & 0,45 & 3,10 & 0,01 & 0,17 & 0,28 & 0,07 & 0,49 & 3,82 & 0,04 & 0,25 & 0,35 & 0,10 \\
\hline & 20 & 0,44 & 3,22 & 0,01 & 0,09 & 0,47 & 0,10 & 0,45 & 3,28 & 0,02 & 0,10 & 0,27 & 0,11 \\
\hline & 25 & 0,41 & 3,52 & 0,03 & 0,27 & 0,60 & 0,35 & 0,46 & 3,70 & 0,02 & 0,10 & 0,27 & 0,11 \\
\hline & 30 & - & - & - & - & - & - & 0,46 & 4,47 & 0,05 & 0,49 & 0,49 & 0,34 \\
\hline & 40 & 0,75 & 16,19 & 0,12 & 5,21 & 1,08 & 0,70 & 0,59 & 9,91 & 0,00 & 3,09 & 1,48 & 0,96 \\
\hline \multirow{7}{*}{8} & 0 & 0,46 & 7,84 & 0,03 & 0,30 & 0,27 & 0,23 & - & - & - & - & - & - \\
\hline & 10 & 0,37 & 2,93 & 0,01 & 0,07 & 0,33 & 0,11 & - & - & - & - & - & - \\
\hline & 15 & 0,56 & 12,28 & 0,03 & 0,62 & - & & - & - & - & - & - & - \\
\hline & 20 & 0,60 & 10,62 & 0,03 & 0,52 & 0,38 & 0,13 & - & - & - & - & - & - \\
\hline & 25 & 0,63 & 11,57 & 0,03 & 0,57 & 0,43 & 0,25 & - & - & - & - & - & - \\
\hline & 30 & 0,82 & 13,23 & 0,15 & 3,36 & 1,94 & 0,84 & - & - & - & - & - & - \\
\hline & 40 & 0,88 & 19,62 & 0,12 & 3,64 & 3,27 & 1,76 & - & - & - & - & - & - \\
\hline
\end{tabular}


ANEXO 1. Continuação

\begin{tabular}{|c|c|c|c|c|c|c|c|c|c|c|c|c|c|}
\hline & 0 & 0,70 & 9,26 & 0,59 & 1,63 & 0,24 & 0,05 & 0,64 & 6,72 & 0,85 & 1,41 & 0,35 & 0,09 \\
\hline & 10 & 0,66 & 7,66 & 0,24 & 0,63 & 0,27 & 0,06 & 0,58 & 6,12 & 0,72 & 1,12 & 0,39 & 0,09 \\
\hline 9 & 20 & 0,46 & 2,69 & 0,04 & 0,19 & 0,39 & 0,11 & 0,34 & 2,34 & 0,05 & 0,07 & 0,43 & 0,15 \\
\hline & 25 & 0,43 & 2,45 & 0,04 & 0,04 & 0,33 & 0,08 & 0,42 & 2,04 & 0,03 & 0,11 & 0,50 & 0,22 \\
\hline & 30 & 0,38 & 2,51 & 0,04 & 0,15 & 1,40 & 0,83 & 0,37 & 1,39 & 0,03 & 0,08 & 2,07 & 1,16 \\
\hline & 40 & 0,37 & 2,34 & 0,03 & 0,06 & 2,13 & 1,17 & 0,37 & 1,63 & 0,04 & 0,04 & 2,53 & 2,83 \\
\hline & 0 & 0,25 & 0,80 & 0,03 & 0,07 & 0,61 & 0,09 & - & - & - & - & - & - \\
\hline & 10 & 0,24 & 0,80 & 0,02 & 0,06 & 0,58 & 0,09 & - & - & - & - & - & - \\
\hline 10 & 20 & 0,28 & 1,21 & 0,02 & 0,09 & 0,52 & 0,10 & - & - & - & - & - & - \\
\hline & 25 & 0,30 & 2,81 & 0,03 & 0,16 & 0,62 & 0,15 & - & - & - & - & - & - \\
\hline & 30 & 0,65 & 10,86 & 0,04 & 0,59 & 0,85 & 0,53 & - & - & - & - & - & - \\
\hline & 40 & 0,87 & 5,71 & 0,72 & 2,86 & 1,65 & 0,67 & - & - & - & - & - & - \\
\hline & 0 & - & - & - & - & - & - & 0,24 & 5,93 & 0,03 & 0,08 & 0,29 & 0,06 \\
\hline & 10 & - & - & - & - & - & - & 0,20 & 6,54 & 0,03 & 0,05 & 0,29 & 0,08 \\
\hline 11 & 20 & - & - & - & - & - & - & 0,38 & 10,15 & 0,03 & 0,10 & 0,37 & 0,12 \\
\hline & 25 & - & - & - & - & - & - & 0,54 & 8,45 & 0,05 & 0,08 & 0,78 & 0,41 \\
\hline & 30 & - & - & - & - & - & - & 0,72 & 7,90 & 0,30 & 0,55 & 11,48 & 0,13 \\
\hline & 40 & - & - & - & - & - & - & 0,84 & 5,99 & 0,36 & 0,91 & 11,23 & 1,96 \\
\hline & 0 & 0,29 & 1,92 & 0,03 & 0,17 & 0,24 & 0,10 & 0,40 & 3,30 & 0,03 & 0,11 & 0,36 & 0,09 \\
\hline & 10 & 0,22 & 1,39 & 0,02 & 0,08 & 0,28 & 0,11 & 0,82 & 4,51 & 0,08 & 0,14 & 2,65 & 0,37 \\
\hline 12 & 20 & 0,55 & 1,27 & 0,03 & 0,08 & 1,42 & 0,64 & 1,04 & 12,01 & 0,33 & 3,06 & 2,01 & 0,63 \\
\hline & 25 & 0,62 & 1,03 & 0,05 & 0,13 & 1,96 & 0,96 & 0,80 & 6,10 & 0,21 & 1,90 & 6,33 & 1,86 \\
\hline & 30 & 0,68 & 0,91 & 0,04 & 0,07 & 10,10 & 1,11 & 1,00 & 6,15 & 0,51 & 4,19 & 10,89 & 0,22 \\
\hline & 40 & 0,94 & 15,83 & 0,32 & 4,13 & 5,09 & 1,13 & 0,81 & 7,96 & 0,21 & 0,82 & 2,06 & 0,40 \\
\hline & 0 & 0,50 & 2,84 & 0,14 & 0,58 & - & - & - & - & - & - & - & - \\
\hline & 10 & 0,32 & 1,69 & 0,07 & 0,09 & - & - & - & - & - & - & - & - \\
\hline & 15 & 0,56 & 11,18 & 0,05 & 0,87 & - & - & - & - & - & - & - & - \\
\hline 13 & 20 & 0,44 & 5,55 & 0,06 & 0,86 & - & - & - & - & - & - & - & - \\
\hline & 25 & 0,38 & 2,27 & 0,06 & 0,25 & - & - & - & - & - & - & - & - \\
\hline & 30 & 0,83 & 10,56 & 0,15 & 0,88 & - & - & - & - & - & - & - & - \\
\hline & 40 & 0,78 & 4,66 & 0,27 & 1,05 & - & - & - & - & - & - & - & - \\
\hline & 0 & 0,46 & 6,96 & 0,08 & 0,44 & 0,35 & 0,11 & 0,42 & 5,52 & 0,05 & 0,38 & 0,37 & 0,21 \\
\hline & 10 & 0,45 & 6,86 & 0,05 & 0,46 & 0,41 & 0,16 & 0,32 & 5,73 & 0,04 & 0,31 & 0,34 & 0,19 \\
\hline 14 & 20 & 0,42 & 6,32 & 0,04 & 0,44 & 0,51 & 0,19 & 0,38 & 5,90 & 0,05 & 0,28 & 0,36 & 0,21 \\
\hline & 25 & 0,41 & 6,27 & 0,04 & 0,37 & 0,54 & 0,18 & 0,43 & 6,00 & 0,17 & 0,44 & 0,62 & 0,43 \\
\hline & 30 & 0,45 & 7,12 & 0,09 & 0,44 & 0,99 & 0,51 & 0,42 & 4,72 & 0,18 & 0,41 & 0,69 & 0,42 \\
\hline అี & 40 & 0,88 & 16,74 & 0,70 & 2,49 & 5,46 & 0,58 & 0,42 & 5,41 & 0,16 & 0,50 & 0,67 & 0,45 \\
\hline
\end{tabular}

